CannTeen: cognitive function in adolescent and adult cannabis users and age-matched controls

THIS IS A PRELIMINARY SCIENTIFIC WORK THAT HAS NOT BEEN PEER REVIEWED

\title{
THE CANNTEEN STUDY: VERBAL EPISODIC MEMORY, SPATIAL WORKING MEMORY, AND RESPONSE INHIBITION IN ADOLESCENT AND ADULT CANNABIS USERS AND AGE-MATCHED CONTROLS
}

\section{Disclaimer: This is preliminary scientific work that has not been peer reviewed.}

\section{Authors}

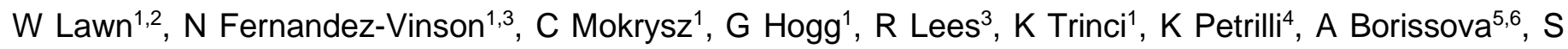
Ofori $^{1}$, S Waters ${ }^{7}$, P Michór ${ }^{8}$, MB Wall ${ }^{1,9}$, TP Freeman ${ }^{1,4}$ \& HV Curran ${ }^{1}$

\section{Affiliations}

1 Clinical Psychopharmacology Unit, University College London, London, United Kingdom.

2 Department of Addictions, Institute of Psychiatry, Psychology and Neuroscience, King's College London, London, United Kingdom.

3 Faculty of Biology, Medicine and Health, University of Manchester, Manchester, United Kingdom

4 Addiction and Mental Health Group (AIM), Psychology Department, University of Bath, Bath, United Kingdom

5 Institute of Psychiatry, Psychology and Neuroscience, King's College London, London, United Kingdom

6 NIHR University College London Hospitals Biomedical Research Centre, University College Hospital, London, United Kingdom.

7 Department of Psychiatry, University of Oxford, Warneford Hospital, Oxford, UK

8 School of Life Sciences, University of Warwick, Coventry, United Kingdom

9 Invicro London, Burlington Danes Building, Hammersmith Hospital, Du Cane Road, London, United Kingdom.

\section{Abstract word count: 226 (word limit 250)}

Main text word count: 4,632

Keywords: cannabis, marijuana, adolescence, response inhibition, memory, working memory, verbal memory, episodic memory, cognition 
CannTeen: cognitive function in adolescent and adult cannabis users and age-matched controls

THIS IS A PRELIMINARY SCIENTIFIC WORK THAT HAS NOT BEEN PEER REVIEWED

\section{Conflict of Interest}

31 No authors have any relevant conflicts of interest to disclose.

33 Financial support

34 This work was supported by a grant from the Medical Research Council (MRC; award number

$35 \mathrm{MR} / \mathrm{P012728/1)}$ to HVC and TPF. AB was funded by a fellowship from the National Institute for Health

36 Research UCLH Biomedical Research Centre. HVC is supported by grants from the MRC, UK Department

37 of Health and by the National Institute for Health Research UCLH Biomedical Research Centre.

\section{Acknowledgments}

40 We would like to thank all of the CannTeen participants for so generously giving up their time to take part.

41 We would also like to thank everyone who contributed to data collection, Invicro staff, and Sharinjeet

42 Dhiman.

43

44 Corresponding author

45 Dr Will Lawn

46 Email: will.lawn@kcl.ac.uk

47

48 National Addiction Centre,

49 Institute of Psychiatry Psychology and Neuroscience,

50 King's College London,

51 Addiction Sciences Building,

524 Windsor Walk,

53 London,

54 SE5 8AF

55 
CannTeen: cognitive function in adolescent and adult cannabis users and age-matched controls THIS IS A PRELIMINARY SCIENTIFIC WORK THAT HAS NOT BEEN PEER REVIEWED

\section{Abstract}

57 Background: Preclinical and human studies suggest that adolescent cannabis use may be associated with worse 58 cognitive outcomes than adult cannabis use. We investigated the associations between chronic cannabis use and 59 cognitive function in adolescent and adult cannabis users and controls. We hypothesised user-status would be negatively associated with cognitive function and this relationship would be stronger in adolescents than adults.

61 Methods: As part of the 'CannTeen' project, this cross-sectional study assessed cognitive performance in adolescent 62 cannabis users $(n=76 ; 16-17$-year-olds), adolescent controls $(n=63)$, adult cannabis users $(n=71 ; 26-29$-year-olds) and 63 adult controls $(n=64)$. Users used cannabis 1-7 days/week. Verbal episodic memory (VEM) was assessed using the prose 64 recall task, spatial working memory (SWM) was assessed using the spatial n-back task, and response inhibition was 65 assessed with the stop-signal task. Primary outcome variables were: delayed recall, 3-back discriminability, and stop 66 signal reaction time, respectively.

67 Results: Users had worse VEM than controls $(F(1,268)=7.423, p=0.007)$. There were no significant differences between 68 user-groups on SWM or response inhibition. Null differences were supported by Bayesian analyses. No significant 69 interactions between age-group and user-group were found for VEM, SWM, or response inhibition.

70 Conclusions: Consistent with previous research, there was an association between chronic cannabis use and poorer

71 VEM, but chronic cannabis use was not associated with SWM or response inhibition. We did not find evidence for 72 heightened adolescent vulnerability to cannabis-related cognitive impairment. 
CannTeen: cognitive function in adolescent and adult cannabis users and age-matched controls THIS IS A PRELIMINARY SCIENTIFIC WORK THAT HAS NOT BEEN PEER REVIEWED

\section{Introduction}

Cannabis is the most commonly used internationally controlled drug by adolescents, with $19 \%$ of English 15 year-olds (NHS-Digital, 2018) and 28\% of American 15-16 year-olds (NIDA, 2020) reporting past-year use. Long-term cannabis use has been linked to compromised cognitive function (Broyd et al., 2016; Curran et al., 2016; Lovell et al., 2020). Predicated on continuing brain development (Blakemore \& Choudhury, 2006; Dumontheil, 2016), the cognitive consequences of adolescent cannabis use are thought to be more severe and enduring than those caused by adult use (Blest-Hopley et al., 2020; Meier et al., 2012). However, direct comparisons between adolescents and adults are lacking.

Throughout adolescence, cognitive abilities are refined as the brain undergoes neurobiological changes, including synaptic pruning and maturation of the endocannabinoid (eCB) system (Ellgren et al., 2008; Larsen \& Luna, 2018; Rubino \& Parolaro, 2016; Verdurand et al., 2011). The eCB system is involved in neuronal reorganisation and the development of cognitive, reward, and executive control brain systems (Fischer et al., 2020; Galve-Roperh et al., 2009; Lu \& MacKie, 2016). Chronic adolescent cannabis exposure may disrupt this maturation (Ellgren et al., 2008; Rubino et al., 2015; Verdurand et al., 2011), which may consequently impair cognition.

Non-human studies of learning and memory have shown adolescent exposure to delta-9-tetrahydrocannabinol (THC) and cannabinoid agonists lead to adult impairments (Rubino \& Parolaro, 2016; Verrico et al., 2014). Some research suggests that adolescent rodents experience greater harm than adult rodents (O'shea et al., 2004; Quinn et al., 2008; Schneider \& Koch, 2003), although recovery after adolescent THC administration to primates has been reported (Verrico et al., 2020). If, and in which domains, human adolescents suffer worse cognitive impacts than adults remains unknown.

Episodic memory is defined as declarative memory for past events and experiences (Tulving, 2002). Verbal episodic memory (VEM) is memory for episodic information that has been presented verbally. Cross-sectional studies have found significantly worse verbal recall in both adolescent (Harvey et al., 2007; Solowij et al., 2011) and adult (Gonzalez et al., 2012) cannabis users, compared to non-users. Additionally, an earlier age of cannabis use onset has been associated with greater verbal recall impairment (Becker et al., 2018; Solowij et al., 2011). Indeed, a meta-analysis revealed that cannabis users performed significantly worse than non-users in both immediate and delayed verbal recall (Schoeler et al., 2016). In sum, after abstinence periods ranging from 12-24 hours, both adult and adolescent cannabis users appear to have impaired episodic memory relative to controls. However, whether adolescents are at greater risk of experiencing these VEM deficits is unknown.

Working memory (WM) refers to the temporary storage and manipulation of information necessary to keep things in mind while performing complex tasks (Baddeley, 2010; Chai et al., 2018). Within the multicomponent model of WM, spatial working memory (SWM) can be defined as the ability to link a visual stimulus to a specific location (Cowan et al., 2006), and is often measured using the spatial n-back task (Green et al., 2005). Much of the previous research in adults has reported null relationships between chronic cannabis use and SWM ability, after both $>24$ hours abstinence (Cousijn, Vingerhoets, et al., 2014; Cousijn, Wiers, et al., 2014b; Desrosiers et al., 2015) and no abstinence (Gonzalez 
CannTeen: cognitive function in adolescent and adult cannabis users and age-matched controls THIS IS A PRELIMINARY SCIENTIFIC WORK THAT HAS NOT BEEN PEER REVIEWED

et al., 2012). However, in a study of nearly 4,000 young adolescents, there was some evidence that cannabis use was associated with compromised SWM capacity (Morin et al., 2019), and more so in females than males (Noorbakhsh et al., 2020). Longitudinal twin studies of young people have revealed contradictory findings regarding the impact of cannabis use over-and-above genetic and familial factors on working memory and other executive functions (Meier et al., 2018; Ross et al., 2020). Other studies in adolescents have been mixed, with some negative associations between cannabis use and SWM (Becker et al., 2018; Harvey et al., 2007; Tervo-Clemmens et al., 2018). Hence, the extant literature tentatively implies that adolescent users may show cannabis-related reductions in SWM capacity, while adults may not.

Response inhibition is the ability to inhibit an action that is no longer appropriate or desired in a specific context, which is crucial for goal-directed behaviour and executive control (Verbruggen \& Logan, 2008). Cross-sectional studies have found no significant differences between adult users and non-users in stop signal reaction time (SSRT) (Gonzalez et al., 2012; Grant et al., 2012) and go/no-go task performance (Hester et al., 2009; Wallace et al., 2020) after varying abstinence periods. Indeed, a meta-analysis reported chronic cannabis use is not associated with motor impulsivity (Figueiredo et al., 2020). However, one study reported worse response inhibition performance in cannabis users relative to controls (Moreno et al., 2012). In adolescents, a marginal association between inhibition errors and cannabis use was reported (Dougherty et al., 2013). Hence, there is a clear lack of behavioural research into response inhibition in cannabis-using adolescents.

Predicated on continued neuropsychological development and some, but not consistent, age-of-onset effects, adolescents were hypothesised to be more vulnerable to the harmful effects of long-term cannabis on cognitive function. When previous research has investigated moderation by age, it has examined the impact of adolescent use on subsequent adult cognition. However, to our knowledge, no studies have directly compared adolescent and adult current cannabis users and controls, while ensuring they are matched on age, gender and cannabis use frequency. Therefore, the differential, contemporary impact on cognitive function of non-acute cannabis use in adolescents and adults is undetermined.

\section{Aims and Hypotheses}

In this study we investigated the relationship between current cannabis use and VEM, SWM and response inhibition in matched adolescents and adults. As registered on the Open Science Framework (OSF; Lawn et al., 2021), our hypotheses were:

1. Cannabis users will have poorer VEM, SWM and response inhibition than controls.

2. There will be user-group by age-group interactions on VEM, SWM and response inhibition, where the user vs. control difference will be greater in adolescents than in adults.

3. Within users, there will be negative associations between frequency of use and task performance, and the relationships will be stronger in adolescents than adult users. 
CannTeen: cognitive function in adolescent and adult cannabis users and age-matched controls THIS IS A PRELIMINARY SCIENTIFIC WORK THAT HAS NOT BEEN PEER REVIEWED

150 For each hypothesis, we also predicted that associations will persist after adjusting for pre-defined covariates (Lawn et al., 2021).

\section{Methods}

\section{Design and Participants}

This is a cross-sectional analysis of baseline data from the longitudinal 'CannTeen' study. The study protocol (Lawn et al., 2020) describes the methods of the project in full. Ethical approval was obtained from the University College London (UCL) ethics committee, (project ID 5929/003). All participants provided written, informed consent, and this study was conducted in line with the Declaration of Helsinki.

The full sample comprises 274 participants: 76 adolescent users, 71 adult users, 63 adolescent controls, and 64 adult controls. Adolescent and adult user and control groups were each matched on age; the two user-groups were matched on cannabis-use frequency. All groups had roughly equivalent numbers of males and females.

For full eligibility criteria, see the supplementary materials. In brief, adolescents were aged 16-17 years and adults aged 26-29 years; users reported using cannabis between 1-7 days/week; adult users were excluded if they had used cannabis on a weekly or more frequent basis before the age of 18; and controls reported using either cannabis or tobacco at least once in their life, but with no more than 10 lifetime uses of cannabis. We recruited controls with limited cannabis or tobacco exposure, rather than people with no exposure, with the aim of more closely matching the controls and users on the opportunity to use drugs and associated unmeasured confounding variables.

Exclusion criteria for all participants were: current treatment for a mental health disorder, current daily use of any psychotropic medication, a personal history of psychotic disorder, or use of any illicit drug except cannabis more than twice per month.

Participants were recruited from online adverts, school assemblies, university campus posters, public posters and flyers, and word-of-mouth.

\section{Measures}

Prose Recall Task

VEM was assessed using the prose recall task from the Rivermead Behavioural Memory Test battery (Wilson et al., 1989). Participants were played a 30 second story via headphones, after which they immediately wrote down what they could remember (i.e. immediate recall). After an approximately 20-minute delay filled with unrelated assessments, participants again wrote down what they could remember from the story (i.e. delayed recall). The story contained 21 'idea units'. For each idea unit, one point was given for a word-perfect recall or exact synonym, and half a point was given for a partial recall or close synonym. The maximum score was therefore 21 . The primary outcome variable was delayed recall, and the secondary outcome variable was immediate recall. 
CannTeen: cognitive function in adolescent and adult cannabis users and age-matched controls THIS IS A PRELIMINARY SCIENTIFIC WORK THAT HAS NOT BEEN PEER REVIEWED

Spatial N-back Task

The spatial n-back task was used as an assessment of SWM (Green et al., 2005). This task was run with PsychoPy software (Peirce et al., 2019). In brief, participants responded to a blue square which appeared sequentially in one of six locations on the screen. They responded 'yes' or 'no' as to whether the square was: (1) in the '12 o'clock' position (0back condition), (2) in the same position as the square in the previous trial (1-back condition), (3) in the same position as the square two trials before (2-back condition), (4) in the same position as the square three trials before (3-back condition). We calculated performance at each load: 0-back, 1-back, 2-back and 3-back. The most sensitive and specific outcome measure of n-back performance is discriminability (d'; Haatveit et al., 2010); $d^{\prime}=Z_{\text {Proportion of Hits }}-Z_{\text {Proportions of False }}$ Alarm. d' on the 3-back condition was the task's primary outcome variable. See supplementary materials for a full task description, secondary outcome variables, and reasons for data exclusion.

\section{Stop Signal Task}

To measure response inhibition, the stop signal task (Verbruggen et al., 2008) was employed. The task was run with PsychoPy software (Peirce et al., 2019). In brief, a series of white arrows appeared sequentially on the screen and participants responded by pressing the appropriate left or right arrow key (go trials). However, on 25\% of the trials, after a variable delay, the arrow turned blue, and participants tried to inhibit their response (stop trials). Staircase tracking of the stop signal delay (SSD) time occurred so that each participant had a $\sim 50 \%$ chance of successful response inhibition, ensuring a reliable stop signal reaction time (SSRT) was calculated, which was the task's primary outcome variable (Verbruggen et al., 2019; Verbruggen \& Logan, 2008); SSRT = mean reaction time on go trials - mean SSD. See supplementary materials for a full task description, secondary outcome variables, and reasons for data exclusion.

\section{Cannabis use measures}

We used a timeline follow-back method (Robinson et al., 2014) to record drug use over the past 12 weeks, and assess cannabis use frequency (in days/week) and days since last use of cannabis. This method has been approved by expert consensus for measuring cannabis use (Lorenzetti et al., 2021). Users also reported the age at which they first used cannabis and how many grams they used on a day of use. Controls reported if they had ever used cannabis and, if so, how many times they had used cannabis in their life.

\section{Other measures and pre-defined covariates}

Other measures included the alcohol use disorder identification test (AUDIT; Babor et al., 2001), cannabis use disorder identification test-revised (CUDIT-R; Adamson et al., 2010), breathalyser and saliva drugs tests. See the supplementary materials for detailed information on these measures. Pre-defined covariates included in analyses were gender, socioeconomic status, risk-taking level (De Haan et al., 2011), premorbid verbal intelligence (Holdnack, 2001), daily tobacco use, twice-weekly alcohol use, and monthly illicit drug, all measured using the timeline follow-back (Robinson et al., 2014).

\section{Procedure}


CannTeen: cognitive function in adolescent and adult cannabis users and age-matched controls THIS IS A PRELIMINARY SCIENTIFIC WORK THAT HAS NOT BEEN PEER REVIEWED

216 As described in the full protocol (Lawn et al., 2020), interested participants were initially pre-screened using an online questionnaire and subsequently screened on the telephone to assess eligibility. Potentially eligible participants were invited to UCL to complete their baseline session. Further eligibility criteria were assessed at the start of the baseline session, including body mass index, an official identification check to verify age, and saliva drugs tests. Breathalyzer tests and self-report were used to confirm recent cannabis ( $>12$ hours), alcohol ( $>12$ hours), and other illicit drug ( $>48$ hours) abstinence. The baseline session then continued with various cognitive, mental health, and behavioural measures, including those described above; the others will be reported elsewhere.

\section{Statistical power}

The project was not powered specifically for this analysis. The project was powered to detect a cross-sectional group difference in cannabis use disorder between adolescent and adult cannabis users, with an odds ratio effect size of three. However, a power calculation based on our number of participants $(n=274)$ indicated that we had $80 \%$ power to detect small age-group by user-group interactions, of size Cohen's $\mathrm{f} \geq 0.17$, at an alpha value of 0.05 .

\section{Statistical Analyses}

Statistical tests were conducted on IBM SPSS Statistics Version 27. Assumptions for parametric analyses were checked (see supplementary materials). For primary analyses, we ran $2 \times 2$ between-subjects factorial ANOVAs. Betweensubjects factors were age-group and user-group. Significant interactions were followed up with Bonferroni-corrected post-hoc pairwise t-tests. For primary outcome variables (delayed recall, d' on 3-back, SSRT), ANCOVAs were then run with the pre-defined covariates included. For primary outcome variables, ANCOVAs were also run in the usergroup only, with a between-subjects factor of age-group and a covariate of cannabis use frequency (days/week) to investigate relationship between the primary outcome variables and cannabis use frequency. We subsequently included pre-defined covariates in these ANCOVAs. For primary outcome variables, when results were non-significant, post-hoc Bayesian independent samples tests were run on SPSS to compare users with controls, and to compare adolescent users with adolescent controls. We assumed equal variances and used a Jeffreys default prior. Bayes factors $\left(\mathrm{BF}_{01}\right) \geq 3$ support the null hypothesis of no difference.

For prose recall, we also performed an exploratory 2x2x2 mixed ANOVA with between-subjects factors of age-group and user-group and a within-subjects factor of time (immediate, delayed). As an additional exploratory analysis, only in adult users, we conducted Pearson correlations between age-of-onset and each primary outcome variable. For secondary outcome variables (see supplementary materials), we conducted 2X2 ANOVAs. When data did not meet assumptions for parametric analyses, we supplemented these with non-parametric Mann-Whitney U-tests. 
CannTeen: cognitive function in adolescent and adult cannabis users and age-matched controls THIS IS A PRELIMINARY SCIENTIFIC WORK THAT HAS NOT BEEN PEER REVIEWED

\section{Results}

\section{Participant characteristics (Tables 1 and 2)}

Demographic and cannabis use variables from the full sample of 274 participants are presented in tables 1 and 2 . In brief, groups were matched on gender and ethnicity. Adolescent users (3.7 days/week; 2.4 days since use) and adult users (4.1 days/week; 2.5 days since use) were matched on cannabis use frequency and days since last use. Adolescent users (17.1 years) and controls (17.1 years) and adult users (27.6 years) and controls (27.4 years) were matched on age. For full details see supplementary materials.

\section{INSERT TABLES $1 \& 2$ HERE}

\section{Prose Recall Task-delayed recall (Figure 1 \& Table 3)}

Two adult users were excluded from prose recall analyses because they received the wrong prose recall story, sample sizes were as follows: adolescent users $n=76$; adolescent controls $n=63$; adult users $n=69$; adult controls $n=64$ (Table 3). Mean values for delayed recall are presented in Table 3.

The interaction between age-group and user-group was non-significant, but at a trend level $(F(1,268)=3.002, p=0.084$, $\left.\eta_{\mathrm{p}}{ }^{2}=0.011\right)$. Exploration of this trend interaction showed that within adults, users performed worse than controls $(t(131)=2.865, p=0.005, \mathrm{MD}=1.272)$, but within adolescents the difference was non-significant $(t(137)=0.443, p=0.659$, $\mathrm{MD}=0.193)$.

There was a significant main effect of age-group $\left(F(1,268)=7.423, p=0.007, \eta_{\mathrm{p}}{ }^{2}=0.027\right)$, with adults (mean $=5.89$, $\mathrm{SD}=2.83$ ) recalling more than adolescents (mean=5.06, $\mathrm{SD}=2.34$ ). There was also a significant main effect of usergroup $\left(F(1,268)=5.533, p=0.019, \eta_{\mathrm{p}}{ }^{2}=0.020\right)$, with controls (mean=5.87, $\left.\mathrm{SD}=2.65\right)$ recalling more than users (mean=5.12, $\mathrm{SD}=2.55$ ). With inclusion of covariates, the significant main effect of age-group persisted, and the trend interaction became less significant $\left(F(1,252)=1.547, p=0.215, \eta_{\mathrm{p}}{ }^{2}=0.006\right.$; see supplementary table $\left.\mathrm{S} 2\right)$. The main effect of user-group became narrowly non-significant $\left(F(1,252)=3.780, p=0.053, \eta_{\mathrm{p}}{ }^{2}=0.015\right)$.

\section{FIGURE $1 \&$ Table 3 HERE}

In users only, the interaction between number of cannabis use days/week and age-group was non-significant $\left(F(1,141)=0.025, p=0.874, \eta_{\mathrm{p}}{ }^{2}<0.001\right)$. There was a non-significant, trend main effect of cannabis use frequency on delayed prose recall $\left(F(1,141)=3.276, p=0.072, \eta_{\mathrm{p}}{ }^{2}=0.023\right)$. Inclusion of covariates did not change this pattern of results (see supplementary table S3).

For immediate recall results see supplementary tables S4 and S5. In brief, the pattern of results for immediate recall was the same as for delayed recall. For the $2 \times 2 \times 2$ mixed ANOVA in which time was included as a within-subjects factor, see supplementary table S11. In brief, immediate recall was better than delayed recall. However, time did not interact with age-group or user-group significantly, and the pattern of results remained similar. 
CannTeen: cognitive function in adolescent and adult cannabis users and age-matched controls THIS IS A PRELIMINARY SCIENTIFIC WORK THAT HAS NOT BEEN PEER REVIEWED

In line with the spatial n-back exclusion criteria, 30 participants were excluded (see supplementary materials). A further 7 participants were excluded due to missing data. After these participants were excluded, sample sizes were as follows: adolescent users $n=62$; adolescent controls $n=59$; adult users $n=58$; adult controls $n=58$ (Table 3 ).

The interaction between age-group and user-group was non-significant $\left(F(1,233)=0.722, p=0.396, \eta_{\mathrm{p}}{ }^{2}=0.003\right)$. Main effects of age-group $\left(F(1,233)=0.289, p=0.591, \eta_{\mathrm{p}}{ }^{2}=0.001\right)$ and user-group $\left(F(1,233)=0.075, p=0.785, \eta_{\mathrm{p}}{ }^{2}<0.001\right)$ were non-significant. This pattern of results was not changed by inclusion of covariates in the ANCOVA (see supplementary table S2). Post-hoc Bayesian analyses supported the null hypothesis of no differences between user-groups $\left(\mathrm{BF}_{01}=9.480\right)$ and between adolescent users and adolescent controls $\left(\mathrm{BF}_{01}=6.519\right)$ in $d$ ' for the 3-back. See figure 1 for mean 3-back d' in each group. For secondary outcome variable results, see supplementary tables S6 and S7. In brief, all but two tests were non-significant, demonstrating no meaningful differences between the groups on the spatial n-back task.

\section{FIGURE 2 HERE}

In users only, the interaction between age-group and cannabis use frequency was non-significant $(F(1,116)=0.313$, $\left.p=0.577, \eta_{\mathrm{p}}{ }^{2}=0.003\right)$. The main effect of cannabis use frequency $\left(F(1,116)=1.138, p=0.288, \eta_{\mathrm{p}}{ }^{2}=0.010\right)$ was also nonsignificant. This pattern of results was unchanged by inclusion of covariates in the ANOVA (see supplementary table S3).

\section{Stop Signal Task - SSRT}

In line with the stop signal task exclusion criteria (see supplementary materials), 16 participants were excluded. Additionally, there were 2 participants with missing data. After these participants were excluded, sample sizes were as follows: adolescent users $n=72$; adolescent controls $n=55$; adult users $n=67$; adult controls $n=62$ (Table 3 ). For the SSRT data, one extreme outlier in the adolescent user-group was found and Winsorized.

The interaction between age-group and user-group was non-significant $\left(F(1,252)=0.458, p=0.499, \eta_{\mathrm{p}}{ }^{2}=0.002\right)$. The main effects of age-group $\left(F(1,252)=2.840, p=0.093, \eta_{\mathrm{p}}{ }^{2}=0.011\right)$ and user-group $\left(F(1,252)=0.391, p=0.532, \eta_{\mathrm{p}}{ }^{2}=0.002\right)$ were also non-significant. Inclusion of covariates in the ANCOVA did not change the pattern of these results (see supplementary table S2). Post-hoc Bayesian analyses supported the null hypothesis of no difference between usergroups $\left(\mathrm{BF}_{01}=8.006\right)$ and between adolescent users and adolescent controls $\left(\mathrm{BF}_{01}=4.935\right)$. Mean SSRT across all groups can be seen in figure 3. For secondary variable results, see supplementary tables S9 and S10. In brief, although the users and controls had equivalent SSRTs, they had different profiles of responding. Users had slower go RTs and responded to go stimuli less accurately than controls, but users responded to stop stimuli more accurately than controls.

\section{FIGURE 3 HERE}

In users only, the interaction between cannabis frequency and age-group was non-significant $(F(1,135)=0.229, p=0.633$, $\left.\eta_{\mathrm{p}}{ }^{2}=0.002\right)$. The main effect of cannabis use frequency was also non-significant $\left(F(1,135)=0.100, p=0.752, \eta_{\mathrm{p}}{ }^{2}=0.001\right)$. This pattern of results did not change with inclusion of covariates in the ANCOVA (see supplementary table S3). 
CannTeen: cognitive function in adolescent and adult cannabis users and age-matched controls THIS IS A PRELIMINARY SCIENTIFIC WORK THAT HAS NOT BEEN PEER REVIEWED

310 Within adult users, there were no significant associations between the age cannabis was first used and VEM, SWM, or response inhibition (see supplementary materials).

\section{Discussion}

This cross-sectional study investigated verbal episodic memory (VEM), spatial working memory (SWM) and response inhibition in adolescent cannabis users, adolescent controls, adult users, and adult controls. Users had worse VEM than controls. There was a trend-level interaction between user-group and age-group, in which adult users performed worse than adult controls, while this was not the case for adolescents. However, this trend interaction did not persist after adjusting for covariates, thus we conclude there is no good evidence for a differential relationship in adolescents and adults. User-group, age-group, and their interaction were not associated with SWM or response inhibition. Indeed, Bayesian analyses supported users and controls having equivalent SWM and response inhibition capacity, across both age-groups and in adolescents only. Within users, there was tentative evidence that cannabis use frequency was negatively associated with VEM, but no evidence that cannabis use frequency was associated with SWM or response inhibition.

In the prose recall task, unadjusted analyses revealed that cannabis users recalled significantly less verbal information after a delay than controls, demonstrating poorer VEM. It is important to note that the effect size was small $\left(\eta_{\mathrm{p}}{ }^{2}=0.020\right)$ and the overlap between the groups was large. This aligns with previous research (Broyd et al., 2016; Gonzalez et al., 2012; Schoeler et al., 2016; Solowij et al., 2011), demonstrating a small but significant deficit in cannabis users compared to controls on delayed recall. After adjusting for our pre-defined covariates, the main effect of user-group became only marginally significant $(\mathrm{p}=0.053)$. This was likely due to some variance in delayed recall being accounted for by the covariates SES and WTAR (see supplementary table S3). However, the user-group main effect remains close to our alpha value and is consistent with most previous research.

Collectively, our results and the extant literature (Broyd et al., 2016; Schoeler et al., 2016) imply there is a weak but significant association between chronic cannabis use and impaired delayed recall. Consistent with our results, in the meta-analysis of 7,697 healthy participants (Schoeler et al., 2016) found a small ( $d=0.39)$ association between chronic cannabis use and poorer verbal delayed recall. In our study, we found an effect size of $\eta_{\mathrm{p}}{ }^{2}=0.020(\mathrm{~d}=0.28)$, with an absolute mean difference of 0.75 words. Since these effect sizes are small, the differences in VEM between users and non-users may not be clinically or educationally meaningful, with little impact on day-to-day life (Scott et al., 2017). Furthermore, this small difference between users and non-users may reverse upon prolonged abstinence (Pope et al., 2001; Schoeler et al., 2016; Scott et al., 2017).

We found a non-significant, but trend, interaction between age-group and user-group on VEM. In contrast to our hypothesis, adult users performed worse than adult controls, but adolescent users did not differ from adolescent controls. Not only was this a trend result, but the interaction was lost after inclusion of covariates. Hence, despite the unadjusted significant interaction, we conclude that adults do not have a stronger relationship between long-term cannabis use and 
CannTeen: cognitive function in adolescent and adult cannabis users and age-matched controls THIS IS A PRELIMINARY SCIENTIFIC WORK THAT HAS NOT BEEN PEER REVIEWED

VEM than adolescents. Previous studies have found that those with an earlier age of cannabis use onset recalled less words than those with a later age-of-onset (Becker et al., 2018; Solowij et al., 2011). Although our adolescent cannabis users had similar age-of-onsets and cannabis use frequency to Solowij and colleagues' users, we found that adolescents were not more vulnerable to the effects of cannabis on VEM.

In contrast to our hypothesis, in both unadjusted and adjusted analyses, we found no significant differences in SWM or response inhibition between cannabis users and controls. Bayesian analyses supported these null results, providing evidence that chronic cannabis use is not associated with either response inhibition or spatial working memory. Our results are consistent with much of the previous research, which has not found evidence for an association between cannabis use and response inhibition (Gonzalez et al., 2012; Grant et al., 2012; Hester et al., 2009; Tapert et al., 2007; Wallace et al., 2020) or SWM (Cousijn, Wiers, et al., 2014b, 2014a; Desrosiers et al., 2015; Grant et al., 2012; Noorbakhsh et al., 2020). In contrast, one large longitudinal cohort study found that, in some but not all analyses, cannabis use over a 4-year period was associated with impaired SWM in adolescents (Morin et al., 2019).

Chronic cannabis use may be associated with reduced VEM, but not SWM or response inhibition, due to neurobiological factors. Research has implicated the hippocampus as an important structure for verbal (Sass et al., 1990) and episodic memory (Vargha-Khadem et al., 1997). The hippocampus has a high density of cannabinoid-1 receptors (CB1Rs) (Herkernham et al., 1991; Moldrich \& Wenger, 2000; Tsou et al., 1997), thus implicating CB1Rs in declarative memory formation. On the other hand, SWM and response inhibition are executive functions and are thought to be more reliant on the prefrontal cortex (Blasi et al., 2006; Horn et al., 2003; Rae et al., 2015), which has a lower CB1R density than the hippocampus (Auclair et al., 2000; Tsou et al., 1997). Hence, any downregulation and desensitisation of CB1Rs with chronic cannabis use may have a weaker functional effect on SWM and response inhibition.

In both the spatial n-back and stop signal task, we found no significant interactions between the age and user-groups. Moreover, the trend interaction on VEM was lost after adjusting for covariates. The equivalence of adolescent users and controls on SWM and response inhibition was supported by Bayesian analyses. Furthermore, we found no significant interactions between age-group and cannabis use frequency. Finally, our exploratory analyses within adult users showed null associations between age-of-onset and task performance. Therefore, our study does not provide any evidence that 16-17-year-old adolescents have an increased vulnerability to cannabis-related VEM, SWM, or response inhibition impairments in comparison to 26-29-year-old adults. Nor does it provide evidence that a younger age-of-onset is associated with poorer cognitive function. Indeed, the overall picture is comprehensively in favour of no adolescent sensitivity.

These results are consistent with some age-of-onset studies, but not others. Crucially, in meta-analyses, null associations between age of cannabis use onset and cognitive function, including working memory and executive function, have been reported (Lovell et al., 2020; Scott et al., 2017). However, earlier age-of-onset has been associated with worse verbal memory in some studies (Becker et al., 2018; Solowij et al., 2011), but not others (Fontes et al., 2011). To reconcile these differences, further studies are required which: (a) longitudinally track adolescents' cognition as they 
CannTeen: cognitive function in adolescent and adult cannabis users and age-matched controls THIS IS A PRELIMINARY SCIENTIFIC WORK THAT HAS NOT BEEN PEER REVIEWED

384 grow up, and (b) compare adolescent cannabis users with adult users who initiated cannabis use at the same time as the adolescents, and adult users who initiated cannabis use after adolescence.

\section{Strengths and Limitations}

Our sample $(n=274)$ is large in comparison to many previous similar studies that have investigated cognitive function in adolescent cannabis users. Furthermore, the novel approach of comparing cannabis-matched adolescents and adults, alongside age- and gender-matched controls, permitted a direct comparison and investigation of adolescent vulnerability to cannabis. Adult cannabis users had not used cannabis frequently before the age of 18 and our controls all had limited exposure to cannabis or tobacco, reducing unmeasured confounding differences with users. Abstinence from all drugs was verified using biological measurements. Moreover, we pre-registered our protocol and analyses, included relevant covariates, and conducted Bayesian tests to support null findings.

Given our participant recruitment strategy, our sample is not representative of the general UK population or UK cannabis users. However, this sampling methodology was required in order to recruit frequent cannabis users and matched controls, and optimise power. This is common in observational drug research (Becker et al., 2018; Jacobus et al., 2015; Morgan et al., 2012), given baseline levels of frequent drug use are low in the general population. This was a crosssectional study, therefore it cannot detect changes in the groups' performance over time, when differences may emerge. Future research should also recruit younger cannabis users to test whether adolescent vulnerability appears at younger ages and ideally compare cannabis users against age-based population norms for cognitive function.

\section{Conclusions}

This cross-sectional study found a significant, but small negative association between chronic cannabis use and VEM. There were no relationships between user-group and response inhibition or SWM. These results were supported by Bayesian analyses. We did not find evidence for an age-specific cannabis vulnerability for VEM, SWM, or response inhibition. These results do not lend support to the hypothesis that adolescents are at greater risk of cannabis-induced cognitive impairment. However, large longitudinal studies of cannabis using and non-using adolescents are needed to confirm this. 
CannTeen: cognitive function in adolescent and adult cannabis users and age-matched controls

THIS IS A PRELIMINARY SCIENTIFIC WORK THAT HAS NOT BEEN PEER REVIEWED

\section{References}

Adamson, S. J., Kay-Lambkin, F. J., Baker, A. L., Lewin, T. J., Thornton, L., Kelly, B. J., \& Sellman, J. D. (2010). An improved brief measure of cannabis misuse: the Cannabis Use Disorders Identification Test-Revised (CUDIT-R). Drug and Alcohol Dependence, 110(1-2), 137-143.

Auclair, N., Otani, S., Soubrie, P., \& Crepel, F. (2000). Cannabinoids modulate synaptic strength and plasticity at glutamatergic synapses of rat prefrontal cortex pyramidal neurons. Journal of Neurophysiology, 83(6), 3287-3293. https://doi.org/10.1152/jn.2000.83.6.3287

Babor, T., Higgins-Biddle, J. C., Saunders, J. B., \& Monteiro, M. G. (2001). The Alcohol Use Disorders Identification Test: Guidelines for use in primary care. Geneva: World Health Organization.

Baddeley, A. (2010). Working memory. Current Biology, 20(4), R136-R140.

Becker, M. P., Collins, P. F., Schultz, A., Urošević, S., Schmaling, B., \& Luciana, M. (2018). Longitudinal changes in cognition in young adult cannabis users. Journal of Clinical and Experimental Neuropsychology, 40(6), 529-543.

Blakemore, S. J., \& Choudhury, S. (2006). Development of the adolescent brain: Implications for executive function and social cognition. In Journal of Child Psychology and Psychiatry and Allied Disciplines. https://doi.org/10.1111/j.1469-7610.2006.01611.x

Blasi, G., Goldberg, T. E., Weickert, T., Das, S., Kohn, P., Zoltick, B., Bertolino, A., Callicott, J. H., Weinberger, D. R., \& Mattay, V. S. (2006). Brain regions underlying response inhibition and interference monitoring and suppression. European Journal of Neuroscience, 23(6), 1658-1664. https://doi.org/10.1111/j.1460-9568.2006.04680.x

Blest-Hopley, G., Colizzi, M., Giampietro, V., \& Bhattacharyya, S. (2020). Is the adolescent brain at greater vulnerability to the effects of cannabis? A narrative review of the evidence. Frontiers in Psychiatry, 11, 859.

Broyd, S. J., van Hell, H. H., Beale, C., Yuecel, M., \& Solowij, N. (2016). Acute and chronic effects of cannabinoids on human cognition—a systematic review. Biological Psychiatry, 79(7), 557-567.

Chai, W. J., Abd Hamid, A. I., \& Abdullah, J. M. (2018). Working memory from the psychological and neurosciences perspectives: a review. Frontiers in Psychology, 9, 401.

Cousijn, J., Vingerhoets, W. A. M., Koenders, L., De Haan, L., Van Den Brink, W., Wiers, R. W., \& Goudriaan, A. E. (2014). Relationship between working-memory network function and substance use: A 3-year longitudinal fMRI study in heavy cannabis users and controls. Addiction Biology, 19(2), 282293. https://doi.org/10.1111/adb.12111

Cousijn, J., Wiers, R. W., Ridderinkhof, K. R., van den Brink, W., Veltman, D. J., \& Goudriaan, A. E. 
CannTeen: cognitive function in adolescent and adult cannabis users and age-matched controls

THIS IS A PRELIMINARY SCIENTIFIC WORK THAT HAS NOT BEEN PEER REVIEWED

(2014a). Effect of baseline cannabis use and working-memory network function on changes in cannabis use in heavy cannabis users: A prospective fMRI study. Human Brain Mapping, 35(5), 24702482.

Cousijn, J., Wiers, R. W., Ridderinkhof, R., van den Brink, W., Veltman, D. J., \& Goudriaan, A. E. (2014b). Effect of Baseline Cannabis Use andWorking-Memory Network Function on Changesin Cannabis Use in Heavy Cannabis Users:A Prospective fMRI Study. Human Brain Mapping, 35, 2470-2482.

Cowan, N., Saults, J. S., \& Morey, C. C. (2006). Development of working memory for verbal-spatial associations. Journal of Memory and Language, 55(2), 274-289.

Curran, Freeman, T. P., Mokrysz, C., Lewis, D. A., Morgan, C. J. A., \& Parsons, L. H. (2016). Keep off the grass? Cannabis, cognition and addiction. Nature Reviews Neuroscience, 17(5), 293-306.

De Haan, L., Kuipers, E., Kuerten, Y., Van Laar, M., Olivier, B., \& Cornelis Verster, J. (2011). The rT-18: a new screening tool to assess young adult risk-taking behavior. International Journal of General Medicine.

Desrosiers, N. A., Ramaekers, J. G., Chauchard, E., Gorelick, D. A., \& Huestis, M. A. (2015). Smoked cannabis' psychomotor and neurocognitive effects in occasional and frequent smokers. Journal of Analytical Toxicology, 39(4), 251-261.

Dougherty, D. M., Mathias, C. W., Dawes, M. A., Furr, R. M., Charles, N. E., Liguori, A., Shannon, E. E., \& Acheson, A. (2013). Impulsivity, attention, memory, and decision-making among adolescent marijuana users. Psychopharmacology, 226(2), 307-319.

Dumontheil, I. (2016). Adolescent brain development. In Current Opinion in Behavioral Sciences. https://doi.org/10.1016/j.cobeha.2016.04.012

Ellgren, M., Artmann, A., Tkalych, O., Gupta, A., Hansen, H. S., Hansen, S. H., Devi, L. A., \& Hurd, Y. L. (2008). Dynamic changes of the endogenous cannabinoid and opioid mesocorticolimbic systems during adolescence: THC effects. European Neuropsychopharmacology, 18(11), 826-834.

Figueiredo, P. R., Tolomeo, S., Steele, J. D., \& Baldacchino, A. (2020). Neurocognitive consequences of chronic cannabis use: a systematic review and meta-analysis. In Neuroscience and Biobehavioral Reviews. https://doi.org/10.1016/j.neubiorev.2019.10.014

Fischer, A. S., Tapert, S. F., Louie, D. L., Schatzberg, A. F., \& Singh, M. K. (2020). Cannabis and the Developing Adolescent Brain. Current Treatment Options in Psychiatry, 7(2), 144-161. https://doi.org/10.1007/s40501-020-00202-2

Fontes, M. A., Bolla, K. I., Cunha, P. J., Almeida, P. P., Jungerman, F., Laranjeira, R. R., Bressan, R. A., \& Lacerda, A. L. T. (2011). Cannabis use before age 15 and subsequent executive functioning. The British Journal of Psychiatry, 198(6), 442-447. 
CannTeen: cognitive function in adolescent and adult cannabis users and age-matched controls

THIS IS A PRELIMINARY SCIENTIFIC WORK THAT HAS NOT BEEN PEER REVIEWED

Galve-Roperh, I., Palazuelos, J., Aguado, T., \& Guzmán, M. (2009). The endocannabinoid system and the regulation of neural development: potential implications in psychiatric disorders. European Archives of Psychiatry and Clinical Neuroscience, 259(7), 371-382.

Gonzalez, R., Schuster, R. M., Mermelstein, R. J., Vassileva, J., Martin, E. M., \& Diviak, K. R. (2012). Performance of young adult cannabis users on neurocognitive measures of impulsive behavior and their relationship to symptoms of cannabis use disorders. Journal of Clinical and Experimental Neuropsychology, 34(9), 962-976.

Grant, J. E., Chamberlain, S. R., Schreiber, L., \& Odlaug, B. L. (2012). Neuropsychological deficits associated with cannabis use in young adults. Drug and Alcohol Dependence, 121(1-2), 159-162.

Green, A., Ellis, K. A., Ellis, J., Bartholomeusz, C. F., llic, S., Croft, R. J., Phan, K. L., \& Nathan, P. J. (2005). Muscarinic and nicotinic receptor modulation of object and spatial n-back working memory in humans. Pharmacology Biochemistry and Behavior, 81(3), 575-584.

Haatveit, B. C., Sundet, K., Hugdahl, K., Ueland, T., Melle, I., \& Andreassen, O. A. (2010). The validity of d prime as a working memory index: Results from the Bergen n-back task. Journal of Clinical and Experimental Neuropsychology, 32(8), 871-880. https://doi.org/10.1080/13803391003596421

Harvey, M. A., Sellman, J. D., Porter, R. J., \& Frampton, C. M. (2007). The relationship between non-acute adolescent cannabis use and cognition. Drug and Alcohol Review, 26(3), 309-319. https://doi.org/10.1080/09595230701247772

Herkernham, M., Lynn, A. B., Johnson, M. R., Melvin, L. S., de Costa, B. R., \& Rice, K. C. (1991). Characterization and Localization of Cannabinoid Receptors in Rat Brain: A Quantitative in vitro Autoradiographic Study. Journal of Neuroscience, 11(2), 563-583.

Hester, R., Nestor, L., \& Garavan, H. (2009). Impaired error awareness and anterior cingulate cortex hypoactivity in chronic cannabis users. Neuropsychopharmacology, 34(11), 2450-2458.

Holdnack, H. A. (2001). Wechsler test of adult reading: WTAR. San Antonio, TX: The Psychological Corporation.

Horn, N. R., Dolan, M., Elliott, R., Deakin, J. F. W., \& Woodruff, P. W. R. (2003). Response inhibition and impulsivity: An fMRI study. Neuropsychologia, 41(14), 1959-1966. https://doi.org/10.1016/S00283932(03)00077-0

Jacobus, J., Squeglia, L. M., Infante, M. A., Castro, N., Brumback, T., Meruelo, A. D., \& Tapert, S. F. (2015). Neuropsychological performance in adolescent marijuana users with co-occurring alcohol use: A three-year longitudinal study. Neuropsychology, 29(6), 829.

Larsen, B., \& Luna, B. (2018). Adolescence as a neurobiological critical period for the development of higher-order cognition. Neuroscience and Biobehavioral Reviews, 94, 179-195. 
CannTeen: cognitive function in adolescent and adult cannabis users and age-matched controls

THIS IS A PRELIMINARY SCIENTIFIC WORK THAT HAS NOT BEEN PEER REVIEWED

Lawn, Mokrysz, C., Borissova, A., Lees, R., Petrilli, K., Bloomfield, M., Wall, M., Freeman, T., \& Curran, H. V. (2020). OSF / cannTEEN: How does long-term cannabis use affect teenagers' and adults' cognition, mental health and brains? https://osf.io/jg9qp/

Lawn, W., Mokrysz, C., Fernandez-Vinson, N., Hogg, G., Petrilli, K., Lees, R., Borissova, A., Ofori, S., Bloomfield, M., Wall, M., Freeman, T., \& Curran, H. (2021). Analysis Plan: Spatial working memory, verbal episodic memory and response inhibition in adolescents and adults who do and do not use cannabis. OSF.

Lorenzetti, V., Hindocha, C., Petrilli, K., Griffiths, P., Brown, J., Castillo-Carniglia, Á., Caulkins, J. P., Englund, A., EISohly, M. A., \& Gage, S. H. (2021). The International Cannabis Toolkit (iCannToolkit): a multidisciplinary expert consensus on minimum standards for measuring cannabis use. Addiction.

Lovell, Akhurst, J., Padgett, C., Garry, M. I., \& Matthews, A. (2020). Cognitive outcomes associated with long-term, regular, recreational cannabis use in adults: A meta-analysis. Experimental and Clinical Psychopharmacology, 28(4), 471-494. https://doi.org/10.1037/pha0000326

Lu, H. C., \& MacKie, K. (2016). An introduction to the endogenous cannabinoid system. Biological Psychiatry, 79(7), 516-525. https://doi.org/10.1016/j.biopsych.2015.07.028

Meier, M. H., Caspi, A., Ambler, A., Harrington, H., Houts, R., Keefe, R. S. E., McDonald, K., Ward, A., Poulton, R., \& Moffitt, T. E. (2012). Persistent cannabis users show neuropsychological decline from childhood to midlife. Proceedings of the National Academy of Sciences, 109(40), E2657-E2664.

Meier, M. H., Caspi, A., Danese, A., Fisher, H. L., Houts, R., Arseneault, L., \& Moffitt, T. E. (2018). Associations between adolescent cannabis use and neuropsychological decline: a longitudinal co-twin control study. Addiction, 113(2), 257-265.

Moldrich, G., \& Wenger, T. (2000). Localization of the CB1 cannabinoid receptor in the rat brain. An immunohistochemical study. Peptides, 21, 1735-1742.

Moreno, M., Estevez, A. F., Zaldivar, F., Montes, J. M. G., Gutiérrez-Ferre, V. E., Esteban, L., SánchezSanted, F., \& Flores, P. (2012). Impulsivity differences in recreational cannabis users and binge drinkers in a university population. Drug and Alcohol Dependence, 124(3), 355-362.

Morgan, C. J. A., Gardener, C., Schafer, G., Swan, S., Demarchi, C., Freeman, T. P., Warrington, P., Rupasinghe, I., Ramoutar, A., Tan, N., Wingham, G., Lewis, S., \& Curra, H. (2012). Sub-chronic impact of cannabinoids in street cannabis on cognition, psychotic-like symptoms and psychological well-being. Psychological Medicine, 42(2), 391-400.

Morin, J.-F. G., Afzali, M. H., Bourque, J., Stewart, S. H., Séguin, J. R., O’Leary-Barrett, M., \& Conrod, P. J. (2019). A population-based analysis of the relationship between substance use and adolescent cognitive development. American Journal of Psychiatry, 176(2), 98-106. 
CannTeen: cognitive function in adolescent and adult cannabis users and age-matched controls

THIS IS A PRELIMINARY SCIENTIFIC WORK THAT HAS NOT BEEN PEER REVIEWED

NHS-Digital. (2018). Smoking, Drinking and Drug Use among Young People in England - NHS Digital. https://digital.nhs.uk/data-and-information/publications/statistical/smoking-drinking-and-drug-useamong-young-people-in-england

NIDA. (2020). Monitoring The Future. National Institute on Drug Abuse.

Noorbakhsh, S., Afzali, M. H., Boers, E., \& Conrod, P. J. (2020). Cognitive function impairments linked to alcohol and cannabis use during adolescence: a study of gender differences. Frontiers in Human Neuroscience, 14, 95.

O'shea, M., Singh, M. E., McGregor, I. S., \& Mallet, P. E. (2004). Chronic cannabinoid exposure produces lasting memory impairment and increased anxiety in adolescent but not adult rats. Journal of Psychopharmacology, 18(4), 502-508.

Peirce, J., Gray, J. R., Simpson, S., MacAskill, M., Höchenberger, R., Sogo, H., Kastman, E., \& Lindeløv, J. K. (2019). PsychoPy2: Experiments in behavior made easy. Behavior Research Methods, 51(1), 195203.

Pope, H. G., Gruber, A. J., Hudson, J. I., Huestis, M. A., \& Yurgelun-Todd, D. (2001). Neuropsychological performance in long-term cannabis users. Archives of General Psychiatry, 58(10), 909-915.

Quinn, H. R., Matsumoto, I., Callaghan, P. D., Long, L. E., Arnold, J. C., Gunasekaran, N., Thompson, M. R., Dawson, B., Mallet, P. E., \& Kashem, M. A. (2008). Adolescent rats find repeated $\Delta$ 9-THC less aversive than adult rats but display greater residual cognitive deficits and changes in hippocampal protein expression following exposure. Neuropsychopharmacology, 33(5), 1113-1126.

Rae, C. L., Hughes, L. E., Anderson, M. C., \& Rowe, J. B. (2015). The prefrontal cortex achieves inhibitory control by facilitating subcortical motor pathway connectivity. Journal of Neuroscience, 35(2), 786794. https://doi.org/10.1523/JNEUROSCI.3093-13.2015

Robinson, S. M., Sobell, L. C., Sobell, M. B., \& Leo, G. I. (2014). Reliability of the Timeline Followback for cocaine, cannabis, and cigarette use. Psychology of Addictive Behaviors. https://doi.org/10.1037/a0030992

Ross, J. M., Ellingson, J. M., Rhee, S. H., Hewitt, J. K., Corley, R. P., Lessem, J. M., \& Friedman, N. P. (2020). Investigating the causal effect of cannabis use on cognitive function with a quasi-experimental co-twin design. Drug and Alcohol Dependence, 206, 107712.

Rubino, T., \& Parolaro, D. (2016). The impact of exposure to cannabinoids in adolescence: Insights from animal models. Biological Psychiatry, 79(7), 578-585. https://doi.org/10.1016/j.biopsych.2015.07.024

Rubino, T., Prini, P., Piscitelli, F., Zamberletti, E., Trusel, M., Melis, M., Sagheddu, C., Ligresti, A., Tonini, R., Di Marzo, V., \& Parolaro, D. (2015). Adolescent exposure to THC in female rats disrupts developmental changes in the prefrontal cortex. Neurobiology of Disease, 73, 60-69. 
CannTeen: cognitive function in adolescent and adult cannabis users and age-matched controls

THIS IS A PRELIMINARY SCIENTIFIC WORK THAT HAS NOT BEEN PEER REVIEWED

https://doi.org/10.1016/j.nbd.2014.09.015

Sass, K. J., Spencer, D. D., Kim, J. H., Westerveld, M., Novelly, R. A., \& Lencz, T. (1990). Verbal memory impairment correlates with hippocampal pyramidal cell density. Neurology, 40(11).

Schneider, M., \& Koch, M. (2003). Chronic pubertal, but not adult chronic cannabinoid treatment impairs sensorimotor gating, recognition memory, and the performance in a progressive ratio task in adult rats. Neuropsychopharmacology, 28(10), 1760-1769.

Schoeler, T., Kambeitz, J., Behlke, I., Murray, R., \& Bhattacharyya, S. (2016). The effects of cannabis on memory function in users with and without a psychotic disorder: findings from a combined metaanalysis. Psychological Medicine, 1, 177-188.

Scott, J. C., Wolf, D. H., Calkins, M. E., Bach, E. C., Weidner, J., Ruparel, K., Moore, T. M., Jones, J. D., Jackson, C. T., \& Gur, R. E. (2017). Cognitive functioning of adolescent and young adult cannabis users in the Philadelphia Neurodevelopmental Cohort. Psychology of Addictive Behaviors, 31(4), 423.

Solowij, N., Jones, K. A., Rozman, M. E., Davis, S. M., Ciarrochi, J., Heaven, P. C. L., Lubman, D. I., \& Yücel, M. (2011). Verbal learning and memory in adolescent cannabis users, alcohol users and nonusers. Psychopharmacology, 216(1), 131-144.

Tapert, S. F., Schweinsburg, A. D., Drummond, S. P. A., Paulus, M. P., Brown, S. A., Yang, T. T., \& Frank, L. R. (2007). Functional MRI of inhibitory processing in abstinent adolescent marijuana users. Psychopharmacology, 194(2), 173-183.

Tervo-Clemmens, B., Simmonds, D., Calabro, F. J., Day, N. L., Richardson, G. A., \& Luna, B. (2018). Adolescent cannabis use and brain systems supporting adult working memory encoding, maintenance, and retrieval. Neurolmage, 169(January 2017), 496-509. https://doi.org/10.1016/j.neuroimage.2017.12.041

Tsou, K., Brown, S., Sanudo-Pena, C., Mackie, K., \& Walker, J. M. (1997). IMMUNOHISTOCHEMICAL DISTRIBUTION OF CANNABINOID CB1 RECEPTORS IN THE RAT CENTRAL NERVOUS SYSTEM. Neuroscience, 83(2), 393-411.

Tulving, E. (2002). EPISODIC MEMORY: From Mind to Brain. Annual Review of Psychology, 53, 1-25.

Vargha-Khadem, F., Gadian, D. G., Watkins, K. E., Connelly, A., Van Paesschen, W., \& Mishkin, M. (1997). Differential effects of early hippocampal pathology on episodic and semantic memory. Science, 277(5324), 376-380.

Verbruggen, F., Aron, A. R., Band, G. P. H., Beste, C., Bissett, P. G., Brockett, A. T., Brown, J. W., Chamberlain, S. R., Chambers, C. D., Colonius, H., Colzato, L. S., Corneil, B. D., Coxon, J. P., Dupuis, A., Eagle, D. M., Garavan, H., Greenhouse, I., Heathcote, A., Huster, R. J., ... Boehler, C. N. (2019). A consensus guide to capturing the ability to inhibit actions and impulsive behaviors in the 
CannTeen: cognitive function in adolescent and adult cannabis users and age-matched controls

THIS IS A PRELIMINARY SCIENTIFIC WORK THAT HAS NOT BEEN PEER REVIEWED

stop-signal task. ELife, 8, 1-26. https://doi.org/10.7554/eLife.46323

Verbruggen, F., \& Logan, G. D. (2008). Response inhibition in the stop-signal paradigm. Trends in Cognitive Sciences, 12(11), 418-424.

Verbruggen, F., Logan, G. D., \& Stevens, M. A. (2008). STOP-IT: Windows executable software for the stop-signal paradigm. Behavior Research Methods, 40(2), 479-483.

Verdurand, M., Nguyen, V., Stark, D., Zahra, D., Gregoire, M.-C., Greguric, I., \& Zavitsanou, K. (2011). Comparison of cannabinoid CB1 receptor binding in adolescent and adult rats: a positron emission tomography study using [18F] MK-9470. International Journal of Molecular Imaging, 2011.

Verrico, C. D., Gu, H., Peterson, M. L., Sampson, A. R., \& Lewis, D. A. (2014). Repeated $\Delta 9$ tetrahydrocannabinol exposure in adolescent monkeys: persistent effects selective for spatial working memory. American Journal of Psychiatry, 171(4), 416-425.

Verrico, C. D., Mathai, D. S., Gu, H., Sampson, A. R., \& Lewis, D. A. (2020). Recovery from impaired working memory performance during chronic $\Delta$-9-tetrahydrocannabinol administration to adolescent rhesus monkeys. Journal of Psychopharmacology, 34(2), 211-220.

Wallace, A. L., Maple, K. E., Barr, A. T., \& Lisdahl, K. M. (2020). BOLD responses to inhibition in cannabisusing adolescents and emerging adults after 2 weeks of monitored cannabis abstinence. Psychopharmacology, 237(11), 3259-3268. https://doi.org/10.1007/s00213-020-05608-7

Wilson, B., Cockburn, J., Baddeley, A., \& Hiorns, R. (1989). The development and validation of a test battery for detecting and monitoring everyday memory problems. Journal of Clinical and Experimental Neuropsychology, 11(6), 855-870. 


\section{Tables}

Table 1. Sociodemographic characteristics of full sample $(n=274)$. AUDIT is the alcohol use disorders identification test. RT-18 is Risk-Taking18. SES is socioeconomic status. WTAR is Wechsler test of adult reading. Daily tobacco refers to non-cannabis cigarettes and roll-ups. Ethnicity is compared using white vs. non-white. WTAR data were missing for 2 adolescent users and 2 adult users. One ethnicity datapoint was missing for adolescent users. SES data were missing for one adolescent user, one adolescent control, three adult users, and one adult control. Continuous data is presented as mean [SD], and categorical data is presented as $n(\%)$. Group differences are highlighted in the final column, ${ }^{*} p<0.05$, ${ }^{* *} p<0.01 .{ }^{* * *} p<0.001$.

\begin{tabular}{|c|c|c|c|c|c|}
\hline & $\begin{array}{l}\text { Adolescent user } \\
\quad(n=76)\end{array}$ & $\begin{array}{c}\text { Adolescent control } \\
(n=63)\end{array}$ & $\begin{array}{l}\text { Adult user } \\
(n=71)\end{array}$ & $\begin{array}{l}\text { Adult control } \\
(\mathrm{n}=64)\end{array}$ & Group differences \\
\hline \multicolumn{6}{|l|}{ Gender: } \\
\hline Female & $38(50.0 \%)$ & $32(50.8 \%)$ & $33(46.5 \%)$ & $33(51.6 \%)$ & \\
\hline Age (years) & $17.1[0.5]$ & $17.1[0.5]$ & $27.6[1.2]$ & 27.4 [1.01] & Adult>adolescent ${ }^{\star * \star}$ \\
\hline \multicolumn{6}{|l|}{ Ethnicity: } \\
\hline Asian & $2(2.7 \%)$ & $10(15.9 \%$ & $11(15.5 \%)$ & $15(23.4 \%)$ & \\
\hline Black & $4(5.3 \%)$ & $2(3.2 \%)$ & $6(8.5 \%)$ & $2(3.1 \%)$ & \\
\hline Other & $3(4.0 \%)$ & $2(3.2 \%)$ & $1(1.4 \%)$ & $2(3.1 \%)$ & \\
\hline Prefer not to say & $0(0.0 \%)$ & $2(3.2 \%)$ & $0(0.0 \%)$ & $1(1.6 \%)$ & \\
\hline $\begin{array}{l}\text { Alcohol use frequency } \\
\text { (days/week) }\end{array}$ & $0.6[0.6]$ & $0.7[0.7]$ & $1.5[1.4]$ & $1.4[1.0]$ & Adult $>$ adolescent ${ }^{\star \star \star}$ \\
\hline
\end{tabular}


CannTeen: cognitive function in adolescent and adult cannabis users and age-matched controls

THIS IS A PRELIMINARY SCIENTIFIC WORK THAT HAS NOT BEEN PEER REVIEWED

Use another illicit drug at least

$45(59.2 \%)$

$2(3.2 \%)$

$18(25.4 \%)$

$1(1.6 \%)$

Users $>$ controls***

once a month (yes)

SES:

$\begin{array}{llllll}\text { Mother's education } & 44(58.7 \%) & 36(58.1 \%) & 31(45.6 \%) & 27(42.9 \%) & \text { Adolescent>adult* }\end{array}$

undergraduate degree or above

$R T-18$

$11.4(3.1)$

$9.1(4.1) \quad 8.8(3.9)$

$7.6(4.1)$

User>control ${ }^{\star \star \star}$

Adolescent $>$ adult ${ }^{\star * *}$

WTAR adjusted

$111.6[9.2]$

110.5 [10.5]

$107.0[9.9]$

110.5 [9.6]

639 
CannTeen: cognitive function in adolescent and adult cannabis users and age-matched controls

THIS IS A PRELIMINARY SCIENTIFIC WORK THAT HAS NOT BEEN PEER REVIEWED

644 Table 2. Cannabis use variables for adolescent users and adult users. Continuous data is presented as mean [SD], and categorical data is 645 presented as $n(\%)$. Data for three adult users is missing for amount of cannabis used on a day of use (for users). Group differences are highlighted 646 in the final column ${ }^{*} p<0.05,{ }^{* *} p<0.01,{ }^{* * *} p<0.001$.

\begin{tabular}{|c|c|c|c|c|c|}
\hline & $\begin{array}{l}\text { Adolescent User } \\
\qquad(\mathrm{n}=76)\end{array}$ & $\begin{array}{l}\text { Adult User } \\
(\mathrm{n}=71)\end{array}$ & $\begin{array}{l}\text { Adolescent Control } \\
\qquad(\mathrm{n}=64)\end{array}$ & $\begin{array}{l}\text { Adult Control }(n= \\
64)\end{array}$ & Group Differences \\
\hline $\begin{array}{l}\text { Days since last cannabis } \\
\text { use }\end{array}$ & $2.4[2.6]$ & $2.5[4.6]$ & $\mathrm{n} / \mathrm{a}$ & $\mathrm{n} / \mathrm{a}$ & \\
\hline $\begin{array}{l}\text { Age (years) of first } \\
\text { cannabis use }\end{array}$ & $14.6[1.1]$ & $18.0[2.9]$ & $\mathrm{n} / \mathrm{a}$ & $\mathrm{n} / \mathrm{a}$ & Adult user>adolescent user* \\
\hline $\begin{array}{l}\text { Cannabis use frequency } \\
\text { (days/week) }\end{array}$ & $3.7[1.9]$ & $4.1[1.9]$ & $\mathrm{n} / \mathrm{a}$ & $\mathrm{n} / \mathrm{a}$ & \\
\hline $\begin{array}{l}\text { Grams of cannabis used } \\
\text { on a day when using }\end{array}$ & $1.1[0.8]$ & $0.6[0.7]$ & $\mathrm{n} / \mathrm{a}$ & $\mathrm{n} / \mathrm{a}$ & Adolescent user>adult user ${ }^{*}$ \\
\hline CUDIT & $15.4[5.6]$ & $11.9[4.8]$ & $\mathrm{n} / \mathrm{a}$ & $\mathrm{n} / \mathrm{a}$ & Adolescent user>adult user* \\
\hline Ever used cannabis (yes) & $\mathrm{n} / \mathrm{a}$ & $\mathrm{n} / \mathrm{a}$ & $55(87.3 \%)$ & $62(96.9 \%)$ & $\begin{array}{l}\text { Adult control>adolescent } \\
\text { control }^{*}\end{array}$ \\
\hline $\begin{array}{l}\text { Number of lifetime } \\
\text { cannabis uses }\end{array}$ & $\mathrm{n} / \mathrm{a}$ & $\mathrm{n} / \mathrm{a}$ & $3.4[2.8]$ & $4.5[3.1]$ & $\begin{array}{l}\text { Adult control>adolescent } \\
\text { control }^{*}\end{array}$ \\
\hline
\end{tabular}


CannTeen: cognitive function in adolescent and adult cannabis users and age-matched controls

THIS IS A PRELIMINARY SCIENTIFIC WORK THAT HAS NOT BEEN PEER REVIEWED

650

651

652

653

\begin{tabular}{lllll}
\hline & Adolescent user & Adolescent control & Adult user & Adult control \\
\hline Prose recall & $\mathrm{n}=76$ & $\mathrm{n}=63$ & $\mathrm{n}=69$ & $\mathrm{n}=64$ \\
$\quad$ Delayed Recall & $4.974[4.383-5.565]$ & $5.167[4.660-5.673]$ & $5.283[4.688-5.886]$ & $6.555[5.800-7.310]$ \\
\hline Spatial $\mathrm{n}$-back & $\mathrm{n}=62$ & $\mathrm{n}=59$ & $\mathrm{n}=58$ & $\mathrm{n}=58$ \\
$\quad$ Mean 3-back $\boldsymbol{d}^{\prime}$ & $1.325[1.113-1.537]$ & $1.262[1.057-1.467]$ & $1.291[1.081-1.501]$ & $1.413[1.168-1.659]$ \\
\hline Stop Signal & $\mathrm{n}=72$ & $\mathrm{n}=55$ & $\mathrm{n}=67$ & $\mathrm{n}=62$ \\
$\quad$ Mean SSRT & $0.264[0.253-0.275]$ & $0.257[0.247-0.267]$ & $0.251[0.243-0.260]$ & $0.252[0.240-0.263]$
\end{tabular}




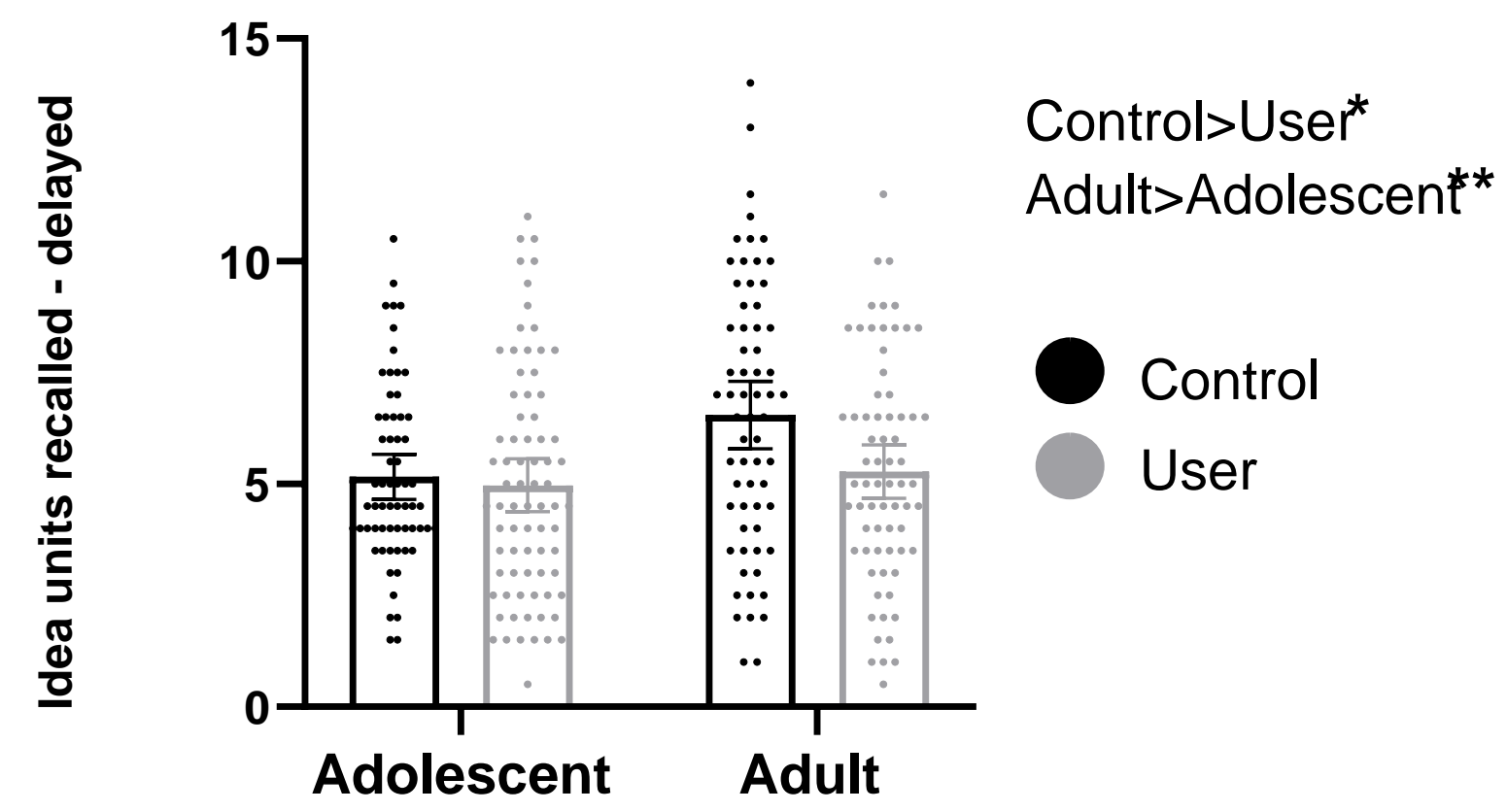

Figures

Figure 1. Mean idea units recalled at the delayed time point with datapoints overlaid, for adolescent users $(n=76)$, adolescent controls $(n=63)$, adult users $(n=69)$ and adult controls $(n=64)$. Error bars represent $95 \%$ confidence intervals. Main effect of age-group was significant at $p<0.01$; main effect of user-group was significant at $p<0.05$; the interaction was trend at $p=0.084$, but not robust to inclusion of covariates. 


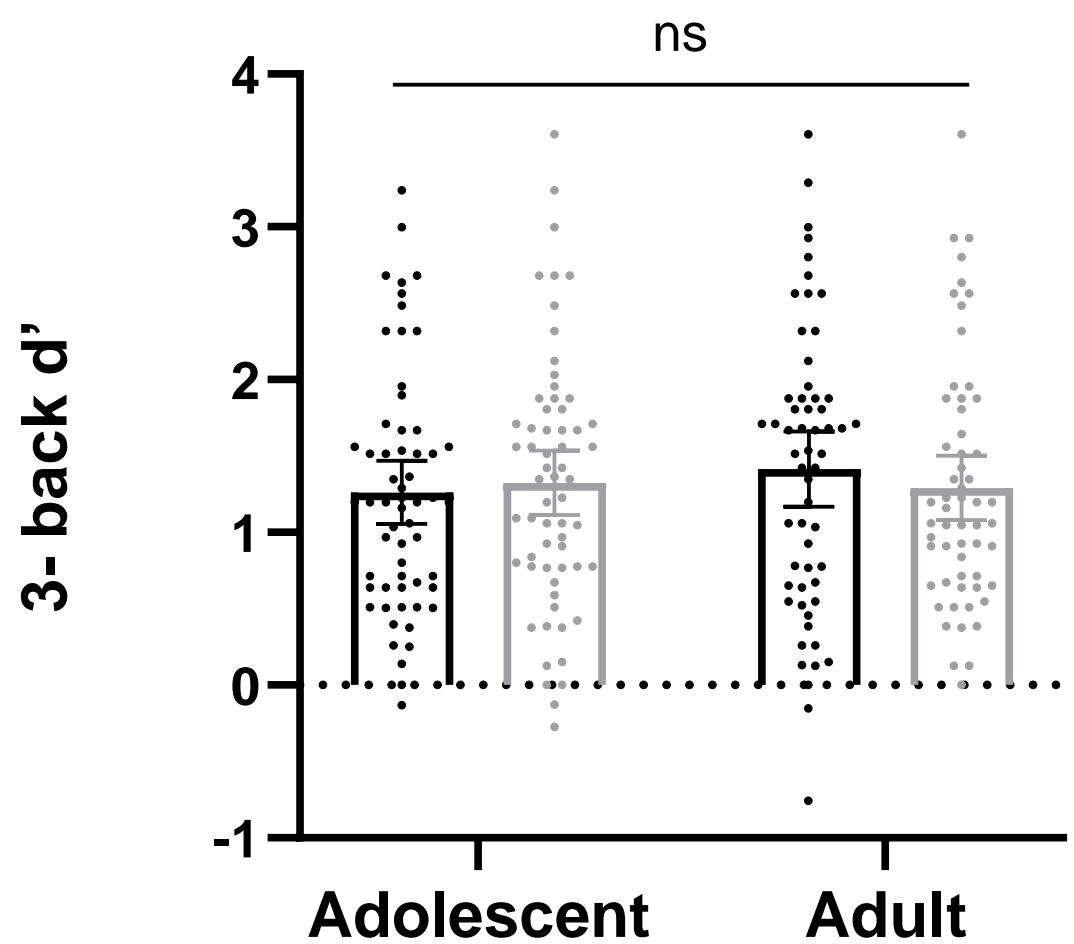
interaction was non-significant.
Control User

Figure 2. Mean 3-back $d$ ' with datapoints overlaid, for adolescent users ( $n=62)$, adolescent controls ( $n=59$ ), adult users ( $n=58$ ) and adult controls $(n=58)$. Error bars represent $95 \%$ confidence intervals. Both age-group and user-group main effects were non-significant, and the 
CannTeen: cognitive function in adolescent and adult cannabis users and age-matched controls

THIS IS A PRELIMINARY SCIENTIFIC WORK THAT HAS NOT BEEN PEER REVIEWED

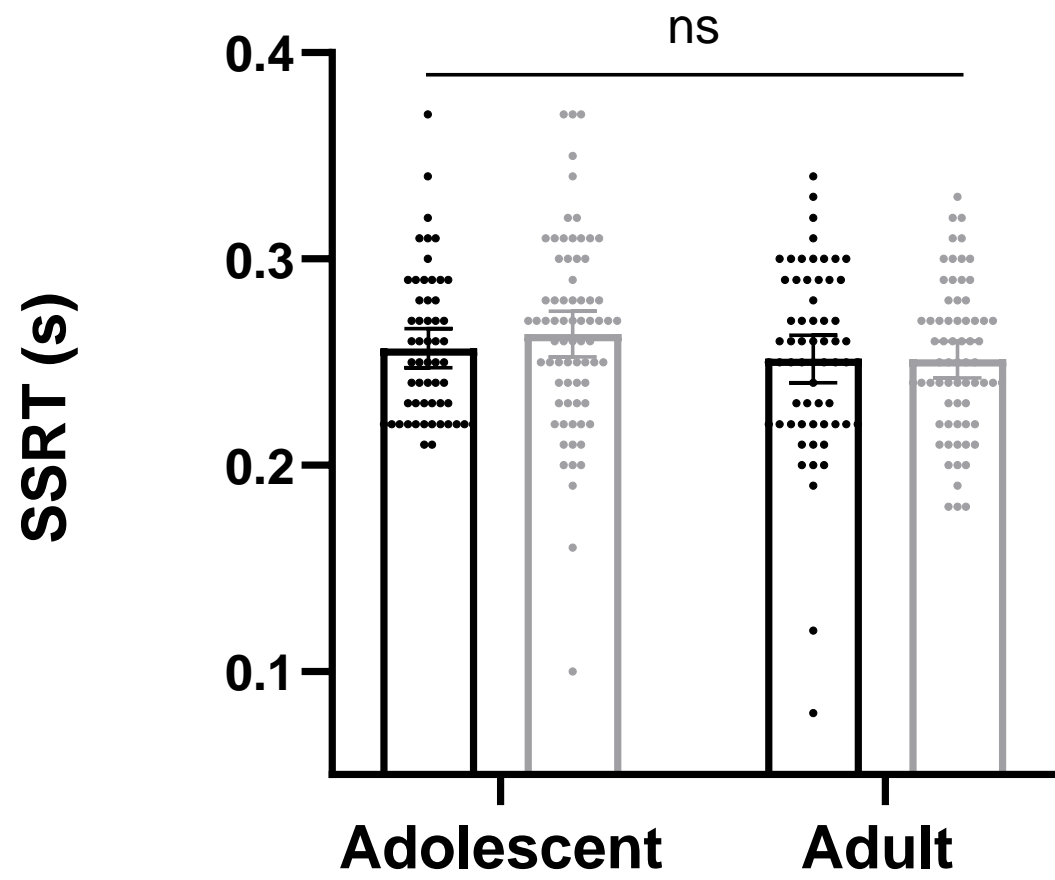
interaction was non-significant.

\section{Adolescent Adult}

Control User

Figure 3. Mean SSRT (in seconds) with datapoints overlaid, for adolescent users ( $n=72$ ), adolescent controls ( $n=55)$, adult users ( $n=67)$ and adult controls ( $n=62$ ). Error bars represent 95\% confidence intervals. Both age-group and user-group main effects were non-significant, and the 
THE CANNTEEN STUDY: VERBAL EPISODIC MEMORY, SPATIAL WORKING

MEMORY, AND RESPONSE INHIBITION IN ADOLESCENT AND ADULT CANNABIS

USERS AND AGE-MATCHED CONTROLS

Disclaimer: This is preliminary scientific work that has not been peer reviewed.

\author{
Authors

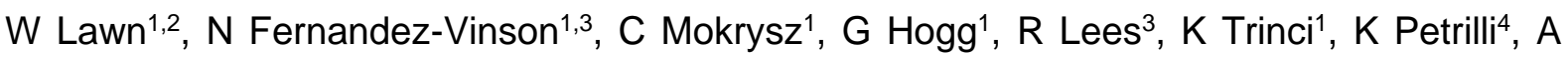

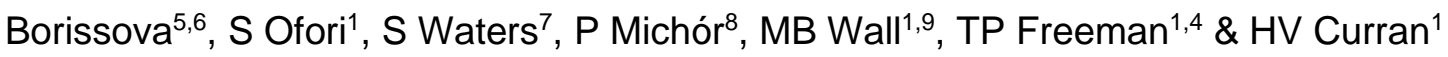

\begin{abstract}
Affiliations
1 Clinical Psychopharmacology Unit, University College London, London, United Kingdom. 2 Department of Addictions, Institute of Psychiatry, Psychology and Neuroscience, King's College London, London, United Kingdom. 3 Faculty of Biology, Medicine and Health, University of Manchester, Manchester, United Kingdom 4 Addiction and Mental Health Group (AIM), Psychology Department, University of Bath, Bath, United Kingdom 5 Institute of Psychiatry, Psychology and Neuroscience, King's College London, London, United Kingdom 6 NIHR University College London Hospitals Biomedical Research Centre, University College Hospital, London, United Kingdom. 7 Department of Psychiatry, University of Oxford, Warneford Hospital, Oxford, UK 8 School of Life Sciences, University of Warwick, Coventry, United Kingdom 9 Invicro London, Burlington Danes Building, Hammersmith Hospital, Du Cane Road, London, United Kingdom.
\end{abstract}

\title{
SUPPLEMENTARY MATERIALS
}

\section{Table of Contents}

Section 1: Supplementary introductory material..................................................................... 2

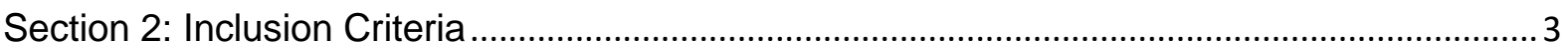

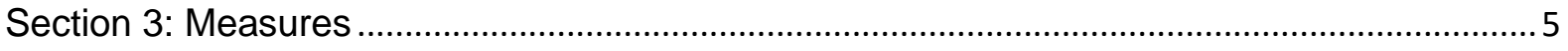

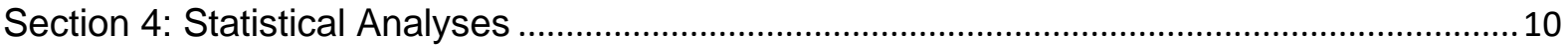

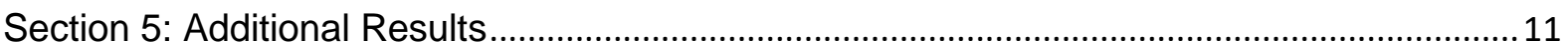

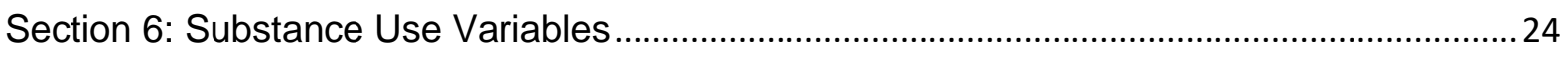

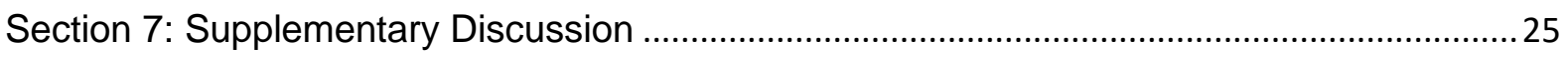


SUPPLEMENTARY CannTeen: cognitive function in adolescent and adult cannabis users and age-matched controls

THIS IS A PRELIMINARY SCIENTIFIC WORK THAT HAS NOT BEEN PEER REVIEWED

\section{Section 1: Supplementary introductory material}

\section{Verbal episodic memory}

Verbal episodic memory (VEM) develops throughout childhood, with some evidence suggesting maturation by 11 years (1), and other research implying continued development until at least 16 years $(2,3)$. A systematic review concluded that verbal memory is one of the cognitive processes most consistently affected by cannabis use (4). Longitudinal studies in adolescents have shown both overall, between-subjects differences between users and controls after cannabis abstinence of 3 weeks (5) and within-subjects prediction of worsening episodic memory performance (6). Furthermore, Jacobus et al. (2015) found that this difference persists after a prolonged period of abstinence (5).

\section{Spatial working memory}

Spatial working memory (SWM) precision increases with age $(7,8)$, with lifetime SWM development following an inverted-U shape pattern, where young adults have better functioning than children and older adults (9).

In one smaller longitudinal study, poorer SWM behavioural performance and SWM neural correlates predicted future cannabis use, but not vice versa (10). Other studies have found that after 12 or more hours abstinence, adolescent cannabis users had significantly worse SWM than age-matched non-using controls (11). However, Becker et al. (2018) found that although adults with adolescent onset cannabis use had poorer working memory than nonusing controls, within the users, age of onset did not moderate this effect.

\section{Response inhibition}

Response inhibition improves throughout childhood $(13,14)$, reaching full maturation around mid-to-late adolescence (15). 


\section{Section 2: Inclusion Criteria}

Table S1. Full inclusion and exclusion criteria (16).

\begin{tabular}{|c|c|c|}
\hline & Inclusion Criteria & Exclusion Criteria \\
\hline All participants & $\begin{array}{l}\text { - Able to come to UCL five times } \\
\text { over the next year } \\
\text { - Capacity to give informed consent } \\
\text { - Normal or corrected-to normal } \\
\text { vision } \\
\text { - Fluent in English }\end{array}$ & $\begin{array}{l}\text { - Any illicit drug use within } 48 \\
\text { hours of the behavioural baseline } \\
\text { session, verified with self-report } \\
\text { and saliva testing } \\
\text { - Any cannabis or alcohol use } \\
\text { within } 12 \text { hours of the } \\
\text { behavioural baseline session, } \\
\text { verified with self-report and } \\
\text { saliva/breathalyser testing. } \\
\text { - Personal history of a diagnosed } \\
\text { psychotic episode or disorder } \\
\text { - Any one illicit drug taken }>2 \\
\text { days/month (averaged over last } 3 \\
\text { months) (except laughing gas) } \\
\text { - Use of laughing gas }>1 \\
\text { day/week (averaged over last } 3 \\
\text { months) } \\
\text { - Receiving treatment for any } \\
\text { mental health condition, including } \\
\text { cannabis dependence, in the last } \\
\text { month } \\
\text { - Unwilling to give blood samples } \\
\text { or likely to faint on blood } \\
\text { sampling } \\
\text { - Current daily use of a } \\
\text { medication which is commonly } \\
\text { psychotropic } \\
\text { - Any mental or physical health } \\
\text { problem judged to be problematic } \\
\text { for the study, by a medical doctor }\end{array}$ \\
\hline $\begin{array}{l}\text { Teenage } \\
\text { cannabis users }\end{array}$ & $\begin{array}{l}\text { - Aged } 16-17 \text { years } \\
\text { - Cannabis use at a frequency of } 1 \text { - } \\
7 \text { days/week (averaged over last } 3 \\
\text { months) }\end{array}$ & $\begin{array}{l}\text { - Age-adjusted } \mathrm{BMI}<2^{\text {nd }} \\
\text { percentile or }>99.6^{\text {th }} \text { percentile }\end{array}$ \\
\hline
\end{tabular}


SUPPLEMENTARY CannTeen: cognitive function in adolescent and adult cannabis users and age-matched controls THIS IS A PRELIMINARY SCIENTIFIC WORK THAT HAS NOT BEEN PEER REVIEWED

\begin{tabular}{|c|c|c|}
\hline $\begin{array}{l}\text { Teenage } \\
\text { controls }\end{array}$ & $\begin{array}{l}\text { - Aged } 16-17 \text { years } \\
\text { - Between } 1 \text { and } 10 \text { days of lifetime } \\
\text { cannabis use or } 0 \text { days of lifetime } \\
\text { cannabis use and at least } 1 \text { day of } \\
\text { lifetime cigarette/roll-up use }\end{array}$ & $\begin{array}{l}- \text { Age-adjusted } \mathrm{BMI}<2^{\text {nd }} \\
\text { percentile or }>99.6^{\text {th }} \text { percentile } \\
\text { - Cannabis use more than once } \\
\text { in the last } 3 \text { months before } \\
\text { behavioural baseline session } \\
\text { - Cannabis use in the month prior } \\
\text { to the behavioural baseline } \\
\text { session }\end{array}$ \\
\hline $\begin{array}{l}\text { Adult cannabis } \\
\text { users }\end{array}$ & $\begin{array}{l}\text { - Aged } 26-29 \text { years } \\
\text { - Cannabis use at a frequency of } 1 \text { - } \\
7 \text { days/week (averaged over last } 3 \\
\text { months) }\end{array}$ & $\begin{array}{l}\text { - Before the age of } 18 \text {, cannabis } \\
\text { use at a frequency of once per } \\
\text { week or more for a period of } 3 \\
\text { months or more. } \\
\text { - BMI }<18.5 \text { or }>34.9\end{array}$ \\
\hline Adult controls & $\begin{array}{l}\text { - Aged } 26-29 \text { years } \\
\text { - Between } 1 \text { and } 10 \text { days of lifetime } \\
\text { cannabis use or } 0 \text { days of lifetime } \\
\text { cannabis use and at least } 1 \text { day of } \\
\text { lifetime cigarette/roll-up use }\end{array}$ & $\begin{array}{l}- \text { Cannabis use more than once } \\
\text { in the last } 3 \text { months before } \\
\text { behavioural baseline session } \\
\text { - Cannabis use in the month prior } \\
\text { to the baseline session } \\
\text { - BMl }<18.5 \text { or }>34.9\end{array}$ \\
\hline
\end{tabular}


SUPPLEMENTARY CannTeen: cognitive function in adolescent and adult cannabis users and age-matched controls THIS IS A PRELIMINARY SCIENTIFIC WORK THAT HAS NOT BEEN PEER REVIEWED

\section{Section 3: Measures}

\section{Stop signal task (figure S1):}

Participants responded to white arrows as they appeared sequentially on the laptop screen (figure S1a). Participants were instructed to press the right arrow key with their right index finger if the arrow was pointing to the right, and the left arrow key with their left index finger if it was pointing to the left (16). $25 \%$ of trials were stop trials, where the white arrow turns blue after a variable delay (figure S1b). Participants were told to inhibit their response if the arrow turned blue. Participants were instructed to respond to the white arrows as quickly and accurately as possible, and not wait for the arrow to turn blue. Each trial lasted $1500 \mathrm{~ms}$, with $500 \mathrm{~ms}$ inter trial intervals. There were 200 trials in total, and therefore 50 stop trials.

Staircase tracking was used to adjust the stop signal delay (SSD, delay between go stimulus onset - white arrow - and stop signal - arrow turns blue) for each stop trial. Initially, the SSD was $250 \mathrm{~ms}$. When the participant successfully inhibited their response, the SSD was increased by $50 \mathrm{~ms}$ for the next stop trial. When the participant was unsuccessful in inhibiting their response, SSD was decreased by $50 \mathrm{~ms}$. This was designed to result in each participant having a $50 \%$ chance of successful response inhibition, so that a reliable stop signal reaction time (SSRT) can be calculated $(17,18)$.

The primary outcome variable for the stop signal task was SSRT, an estimation of the latency of the stop process $(17,18)$. SSRT is calculated according to the mean method, where SSRT = mean RT on go trials - mean SSD (19). Secondary outcome variables were mean SSD, mean go RT, go trial \% correct and stop trial \% correct. Participants were excluded if: their probability of responding to a stop signal was lower than $25 \%$ or higher than $75 \%$, percentage of correct go responses was below $80 \%$, percentage of go errors was higher than $10 \%$ or if their SSRT was below 50ms. Go trials were deemed successful even if the opposite button was pressed relative to the arrow that was presented. However, as stated, participants were excluded if this happened $>10 \%$ of the time; this only happened once. For those included, 18 participants had $>4$ trials in which they pressed the incorrect button direction. 
Figure S1. The stop-signal task. (a) Example of a go trial. A white arrow appears on the screen, without turning blue. Participants must press either the left or right arrow key, depending on which way the arrow is pointing. (b) Example of a stop trial. The white arrow appears on the screen, which then turns blue after a variable delay. Participants are instructed to inhibit their response and not press any key (16).

(a)

$$
\text { Go trial }
$$

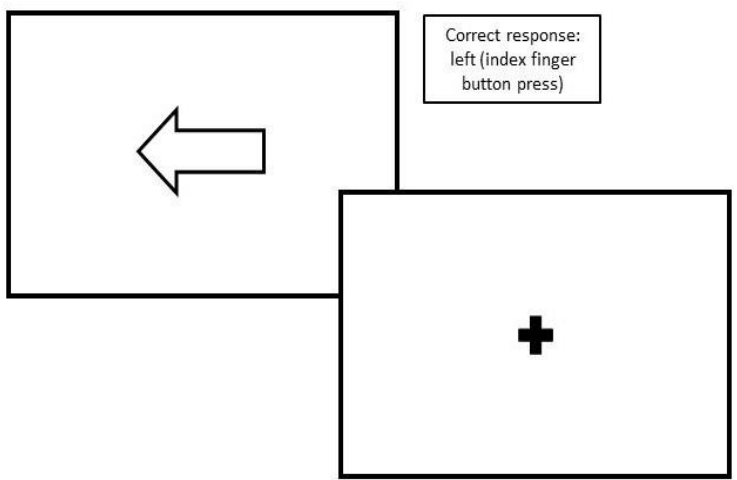

b)

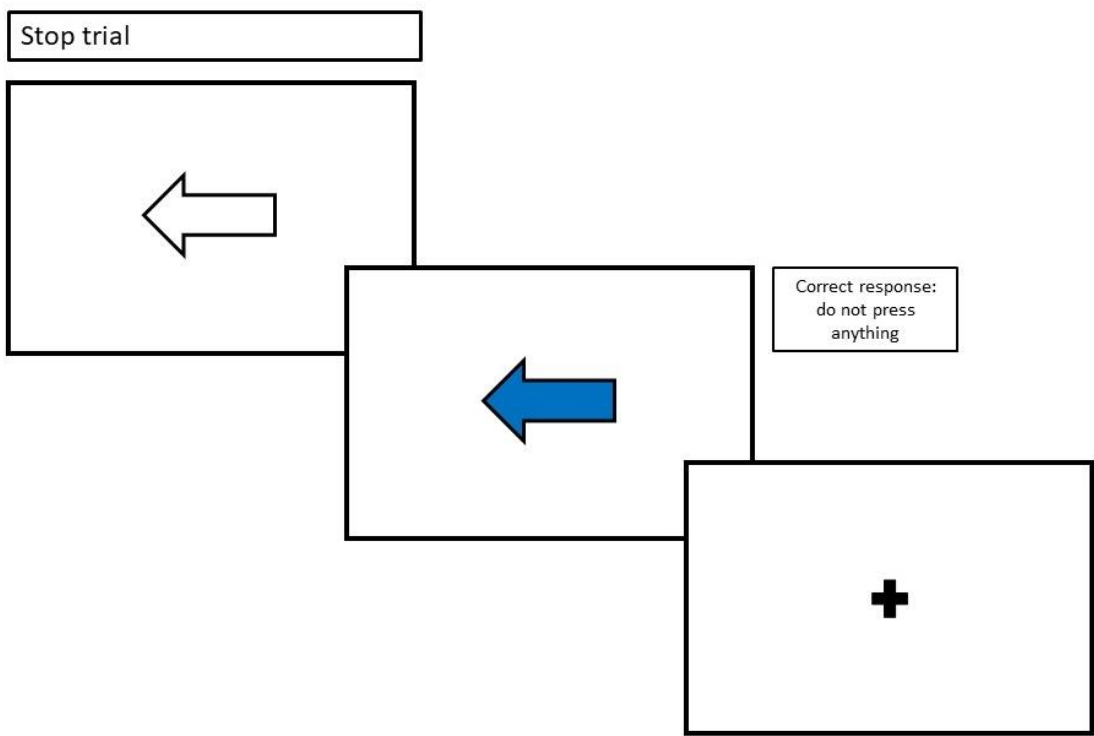


SUPPLEMENTARY CannTeen: cognitive function in adolescent and adult cannabis users and age-matched controls THIS IS A PRELIMINARY SCIENTIFIC WORK THAT HAS NOT BEEN PEER REVIEWED

\section{Spatial n-back task (figure S2):}

First, a blue square was presented to the participant at one of six positions on the screen around a central fixation point for $600 \mathrm{~ms}$. There was a pause of $1500 \mathrm{~ms}$ before the next square. One trial lasts $2100 \mathrm{~ms}$ in total. Responses were only recorded if made before the end of each trial. This task had four conditions: 0-back, 1-back, 2-back and 3-back, appearing in this order. New instructions appeared before each condition. Each condition contained 20 'yes' and 20 'no' trials. The running task time is 5 minutes and 36 seconds. Participants were reminded to respond as quickly and accurately as possible.

In the 0-back condition, the participant must determine if the square is in the ' 12 o'clock' position (by pressing the left index finger button indicating 'yes') or in one of the other five positions (by pressing the right index finger button indicating 'no'). In the 1-back condition, the participant must determine if the square appears in the same position as the square presented one trial before ('yes' trial, target) or in a different position ('no' trial, non-target). In the 2-back condition, the participant must determine if the square is in the same position as the square presented two trials before it ('yes' trial, target) or in a different position ('no' trial, non-target). In the 3-back condition, the participant must determine if the square is in the same position as the square presented three trials before it ('yes' trial, target) or in a different position ('no' trial, non-target)

We calculated performance at each load: 0-back, 1-back, 2-back and 3-back. The most sensitive and specific outcome measure of n-back performance is discriminability (d') (20). This is calculated by: $d^{\prime}=Z_{\text {Proportion of Hits }}-Z_{\text {Proportions of False Alarm. }}$ Proportion of hits $=$ number of successful hits/number of targets. Proportion of false alarms $=$ number of false alarms/number of non-targets.

If proportions of hits is equal to 1 , this is replaced by $1-1 /\left(2^{*}\right.$ number of targets). In this task, 1 is therefore replaced by $1-1 / 40=0.975$. If the proportion of false alarms is equal to 0 , this is replaced by $1 /\left(2^{*}\right.$ number of non-targets). In this task 0 is therefore replaced by $1 / 40=0.025$. We analysed performance at each load separately, however the primary outcome variable was d' in the 3-back condition. Participants who did not successfully complete the task, who either reacted in under $150 \mathrm{~ms}$ on $\geq 5$ trials in any one condition, or who 'missed' $\geq 5$ trials, were excluded from statistical analyses. Secondary outcome variables were d' in the 0-back, 1-back and 2-back conditions, as well as RT and \% trials correct for all conditions. 
Figure S2. Spatial n-back task. A) 0-back; Participant must determine if the square is in the '12 o'clock' position (by pressing 'yes' button on keyboard) or elsewhere (by pressing 'no'). B) 1-back; Participant must determine if the square appears in the same position as the square presented one trial before ('yes' trial, target) or elsewhere ('no' trial, non-target). C) 2 back; Participant must determine if the square is in the same position as the square presented two trials before it ('yes' trial, target) or elsewhere ('no' trial, non-target). D) 3back; Participant must determine if the square is in the same position as the square presented three trials before it ('yes' trial, target) or elsewhere ('no' trial, non-target) (16).

a)

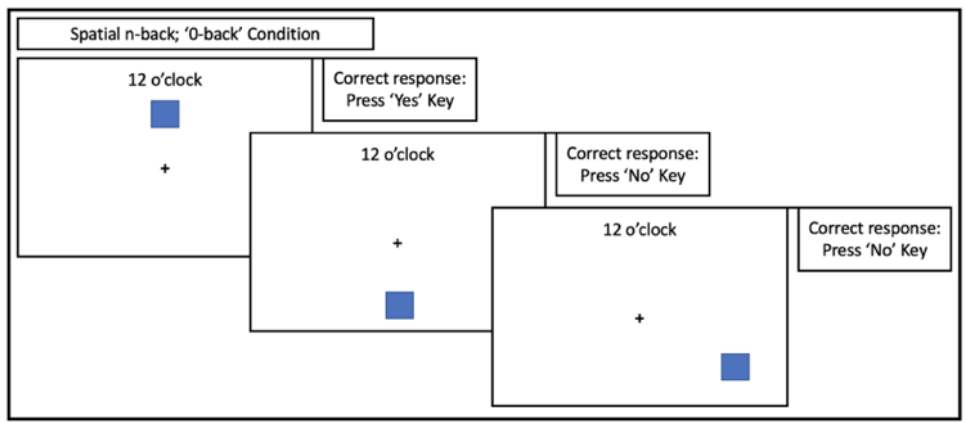

b)

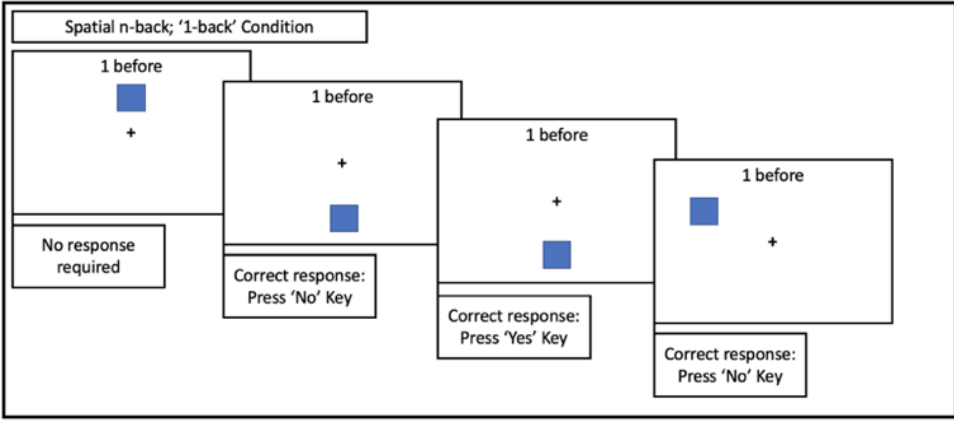

c)

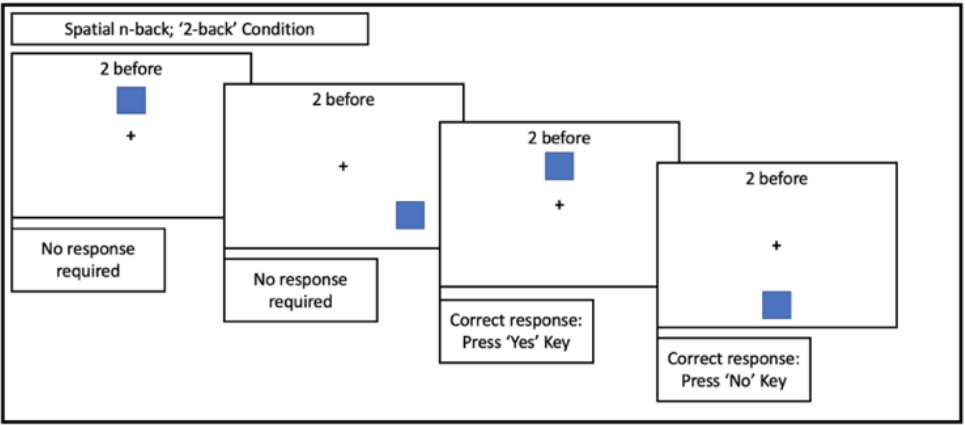

d)

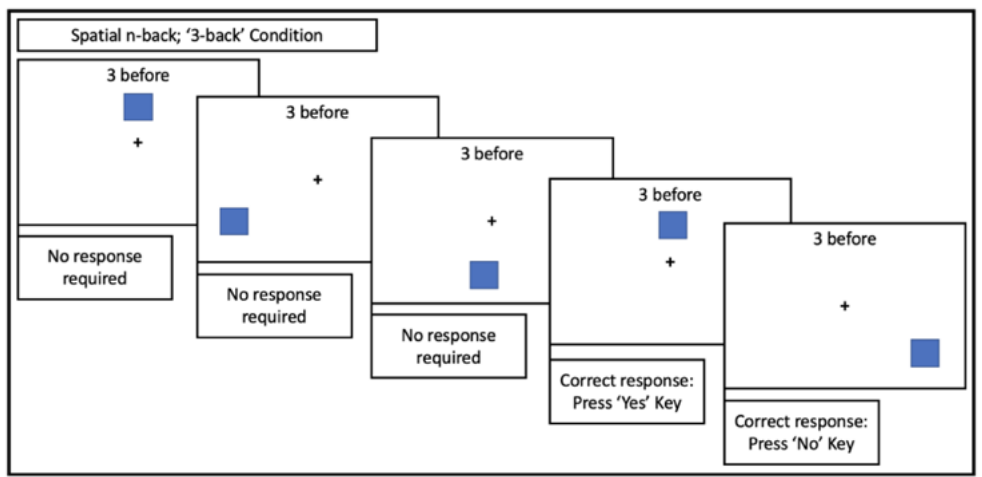


SUPPLEMENTARY CannTeen: cognitive function in adolescent and adult cannabis users and age-matched controls THIS IS A PRELIMINARY SCIENTIFIC WORK THAT HAS NOT BEEN PEER REVIEWED

Gender: Female (coded 0) or male (coded 1)

Substance use frequency: Cannabis, alcohol, tobacco and illicit drug use frequency were all assessed using the TLFB method (21). Participants were prompted to recall the days on which they used these drugs in the 12 weeks prior to baseline. An average use frequency for each drug was calculated in days/week. Participants were categorized into the following groups: Alcohol use $\geq 2$ days/week (coded 1) or Alcohol use $<2$ days/week (coded 0 ); daily cigarette or roll-up tobacco use ( $\geq 6.5$ days/week) (coded 1 ) or non-daily use (coded 0 ); and illicit drug use $\geq 1$ day/month (coded 1) or illicit drug use $<1$ day/month (coded 0 ).

Risk-Taking 18 (RT18): An 18-item questionnaire assessing risk-taking behaviour. Total scores range from 0-18, with higher scores indicating higher levels of risk taking behaviour

Socio-economic status (SES): Assessed using participants' mother's educational level. Participants are categorized into those whose mothers have an educational level of undergraduate degree or above (coded 1), and those whose mothers have an educational level below undergraduate degree (coded 0 ).

Premorbid verbal intelligence: Assessed using the Wechsler test of adult reading (WTAR) (23). Participants read a list of 50 words out loud and were marked on correct pronunciation. Scores were age adjusted scores and standardized to a normal IQ scale, with mean 100 . Scores below 85 were replaced with the value 85 .

Alcohol Use Disorder Identification Test (AUDIT): A 10-item questionnaire assessing hazardous drinking and dependence. Scores range from 0-40 (24).

Cannabis Use Disorder Identification Test- Revised (CUDIT-R): An 8-item questionnaire assessing hazardous cannabis use and dependence. Scores range from 0-32 (25)

Breathalyzer Test: Participants blood alcohol levels were assessed using a Lion Alcometer 500 breathalyzer at baseline, to check alcohol abstinence. Only those with a blood alcohol of 0 completed the session.

Saliva drug tests: Instant saliva drugs tests (either Alere DDSV 703 or ALLTEST DSD867MET/C) were administered at baseline, assessing THC, opiates, benzodiazepine, methamphetamine, amphetamine and opiates in saliva. Only those with negative saliva tests for all drugs completed the session. 
SUPPLEMENTARY CannTeen: cognitive function in adolescent and adult cannabis users and age-matched controls THIS IS A PRELIMINARY SCIENTIFIC WORK THAT HAS NOT BEEN PEER REVIEWED

\section{Section 4: Statistical Analyses}

\section{Power}

The project was not powered specifically for this analysis. The project was powered to detect a cross-sectional group difference in cannabis use disorder between adolescent and adult cannabis users (16), with Cohen's $d=0.6, a=0.05$, power $=0.95$, requiring 148 users. We in fact recruited 147 users and therefore recruited a similar number of controls. Crucially, in terms of detecting age-group by user-group interactions in this baseline data $(n=274)$, with an assumed power of 0.95 we are powered to detect small to medium interactions of size $\mathrm{f} \geq 0.22$, and with an assumed power of 0.8 we are powered to detect small to medium interactions of size $\mathrm{f} \geq 0.17$.

\section{Primary and secondary analyses}

For the stop signal task, the primary outcome variable was SSRT. Secondary outcome variables were mean SSD, mean go RT, stop trial \% correct and go trial \% correct.

For the prose recall task, the primary outcome variable was the number of idea units recalled at the delayed time point. The secondary outcome variable was the number of idea units recalled at the immediate time point.

For n-back, the primary outcome variable was 3-back d'. The secondary outcome variables were 0-back, 1-back and 2-back d', RT and \% trials correct, in addition to 3-back RT and \% trials correct.

\section{Statistical Assumptions}

For ANOVAs and ANCOVAs, Levene's test of equality of variances was checked, and found to be non-significant unless otherwise stated. Homogeneity of variance was also checked by inspecting graphs of Predicted $(\mathrm{x}$ ) vs Residual ( $\mathrm{y}$ ) values. Variance was found to be homogenous, unless otherwise stated. Normality of residuals were checked using Kolmogorov-Smirnov tests and visual inspection of histograms, and residuals were found to have a normal distribution unless otherwise stated. Maximum Cook's distances were calculated and found to be small $(<1)$, with the majority being $<0.3$. For ANCOVAs, multicollinearity was checked by running correlations between predictors. Unless otherwise stated, correlations between predictors were $r<0.45$, indicating that multicollinearity was not an issue. An interim analysis was conducted before all data were collected, when C. Mokrysz presented data at a conference. Hypotheses remained the same throughout and data analysis was not affected. 
SUPPLEMENTARY CannTeen: cognitive function in adolescent and adult cannabis users and age-matched controls THIS IS A PRELIMINARY SCIENTIFIC WORK THAT HAS NOT BEEN PEER REVIEWED

\section{Section 5: Additional Results}

\section{Participant characteristics (see Tables 1 and 2)}

All groups had a similar number of males and females. Adolescent users (3.7 days/week) and adult users (4.1 days/week) were matched on cannabis use frequency $\left(t_{145}=1.198, p=0.233\right.$, $\mathrm{d}=0.198$ ). The time since last cannabis use was similar for adolescent users ( 2.4 days) and adult users ( 2.5 days) ( $\left.\mathrm{t}_{145}=0.118, \mathrm{p}=0.906, \mathrm{~d}=0.019\right)$. Adolescent users ( 17.1 years) and adolescent controls (17.1 years) were matched on age $\left(t_{137}=0.224, p=0.823, d=0.038\right)$, as were adult users (27.6 years) and adult controls (27.4 years) $\left(t_{145}=1.232, p=0.220, d=0.212\right)$.

Significantly more adolescents were in the high SES category than adults $\left(\chi^{2}{ }_{1}=5.345\right.$, $p=0.021)$, they used alcohol less frequently than adults $\left(F_{1,270}=44.114, p<0.001, \eta_{p}{ }^{2}=0.140\right)$, and they had higher RT-18 scores than adults $\left(F_{1,270}=21.077, p<0.001, \eta_{p}{ }^{2}=0.072\right)$.

Users had higher AUDIT score than controls $\left(F_{1,270}=7.099, p=0.008, \eta_{p}^{2}=0.026\right)$, they were more likely to use tobacco on a daily basis than controls $\left(\chi^{2}{ }_{1}=8.467, p=0.004\right)$, they had higher RT-18 scores than controls $\left(F_{1,270}=14.847, p<0.001, \eta_{p}{ }^{2}=0.052\right)$, and were more likely to use other illicit drugs on a monthly basis than controls $\left(\chi^{2}{ }_{1}=61.103, p<0.001\right)$. Additionally, adolescent users were more likely to use another illicit drug on a monthly basis than adult users $\left(\chi^{2}{ }_{1}=17.183, p<0.001\right)$.

For controls, adults had used cannabis slightly more times (4.5) in their life than adolescents (3.4) ( $\mathrm{t}_{125}=2.067, \mathrm{p}=0.041, \mathrm{~d}=0.367$ ) (Table 2). For users, adolescents (14.6 years) first tried cannabis at an earlier age than adults (18.5 years) $\left(\mathrm{t}_{144}=9.647, \mathrm{p}<0.001, \mathrm{~d}=1.598\right)$ and they reported using more cannabis $(1.1 \mathrm{~g})$ on a day of use than adults $(0.6 \mathrm{~g})\left(\mathrm{t}_{142}=3.623, \mathrm{p}<0.001\right.$, $d=0.605)$. 
Table S2: Full ANCOVA results, with pre-defined covariates, for primary outcome variables SSRT, 3-back d' and delayed recall. RT-18 = risk-taking 18; Alcohol = twice-weekly alcohol use; tobacco = daily cigarette or roll-up use; other illicit drugs = monthly use of any other illicit drug; SES = socioeconomic status (maternal education); WTAR = Wechsler test of adult reading.

\begin{tabular}{|c|c|c|c|c|}
\hline & $\mathbf{F}$ & df & $\mathbf{p}$ & $\eta_{p}^{2}$ \\
\hline \multicolumn{5}{|c|}{$\begin{array}{l}\text { Prose recall - delayed recall } \\
\text { score }\end{array}$} \\
\hline User-Group & 3.780 & 1,252 & .053 & .015 \\
\hline Age-Group & 9.351 & 1,252 & .002 & .036 \\
\hline User-Group*Age-Group & 1.547 & 1,252 & .215 & .006 \\
\hline Gender & 1.611 & 1,252 & .206 & .006 \\
\hline RT-18 & 0.142 & 1,252 & .706 & .001 \\
\hline Alcohol & 0.994 & 1,252 & .320 & .004 \\
\hline Tobacco & 0.754 & 1,252 & .386 & .003 \\
\hline Other illicit drugs & 0.468 & 1,252 & .495 & .002 \\
\hline SES & 10.747 & 1,252 & .001 & .041 \\
\hline WTAR & 13.378 & 1,252 & $<.001$ & .050 \\
\hline \multicolumn{5}{|c|}{$\begin{array}{l}\text { Spatial n-back - d' in the 3- } \\
\text { back }\end{array}$} \\
\hline User-Group & 0.938 & 1,219 & .334 & .004 \\
\hline Age-Group & 0.992 & 1,219 & .338 & .004 \\
\hline User-Group*Age-Group & 1.361 & 1,219 & .245 & .006 \\
\hline Gender & 13.191 & 1,219 & $<.001$ & .057 \\
\hline RT-18 & 3.249 & 1,219 & .073 & .015 \\
\hline Alcohol & 7.879 & 1,219 & .005 & .035 \\
\hline Tobacco & 0.204 & 1,219 & .652 & .001 \\
\hline Other illicit drugs & 2.144 & 1,219 & .145 & .010 \\
\hline SES & 0.522 & 1,219 & .471 & .002 \\
\hline WTAR & 3.950 & 1,219 & .048 & .018 \\
\hline \multicolumn{5}{|l|}{ Stop Signal Task- SSRT } \\
\hline User-Group & 0.410 & 1,237 & .523 & .002 \\
\hline Age-Group & 2.782 & 1,237 & .097 & .012 \\
\hline User-Group*Age-Group & 0.398 & 1,237 & .529 & .002 \\
\hline Gender & 0.024 & 1,237 & .878 & $<.001$ \\
\hline RT-18 & 1.854 & 1,237 & .175 & .008 \\
\hline Alcohol & 0.554 & 1,237 & .457 & .002 \\
\hline Tobacco & 4.278 & 1,237 & .040 & .018 \\
\hline Other illicit drugs & 0.104 & 1,237 & .747 & $<.001$ \\
\hline SES & 0.070 & 1,237 & .792 & $<.001$ \\
\hline WTAR & 8.671 & 1,237 & .004 & .035 \\
\hline
\end{tabular}


Table S3: Full results from ANCOVA analyses only in users, with cannabis use frequency in days/week as a covariate. RT-18 = risk-taking 18; Alcohol = twice-weekly alcohol use; tobacco $=$ daily cigarette or roll-up use; other illicit drugs $=$ monthly use of any other illicit drug; SES = socioeconomic status (maternal education); WTAR $=$ Wechsler test of adult reading.

\begin{tabular}{|c|c|c|c|c|}
\hline & $\mathbf{F}$ & df & $\mathbf{p}$ & $\eta_{p^{2}}$ \\
\hline \multicolumn{5}{|l|}{$\begin{array}{l}\text { Prose recall - delayed recall } \\
\text { score }\end{array}$} \\
\hline Age-Group & 2.174 & 1,127 & .143 & .017 \\
\hline Cannabis frequency & 3.705 & 1,127 & .056 & .028 \\
\hline Age-Group*Cannabis Frequency & 0.400 & 1,127 & .528 & .003 \\
\hline Gender & 4.745 & 1,127 & .031 & .036 \\
\hline RT-18 & 0.016 & 1,127 & .900 & $<.001$ \\
\hline Alcohol & 0.098 & 1,127 & .755 & .001 \\
\hline Tobacco & 0.010 & 1,127 & .922 & $<.001$ \\
\hline Other illicit drugs & 0.902 & 1,127 & .344 & .007 \\
\hline SES & 7.224 & 1,127 & .008 & .054 \\
\hline WTAR & 4.272 & 1,127 & .041 & .033 \\
\hline \multicolumn{5}{|l|}{ Spatial n-back - d' in the 3-back } \\
\hline Age-Group & 0.140 & 1,104 & .709 & .001 \\
\hline Cannabis frequency & 1.025 & 1,104 & .314 & .010 \\
\hline Age-Group*Cannabis frequency & 0.027 & 1,104 & .870 & $<.001$ \\
\hline Gender & 9.845 & 1,104 & .002 & .086 \\
\hline RT-18 & 7.890 & 1,104 & .006 & .071 \\
\hline Alcohol & 0.090 & 1,104 & .764 & .001 \\
\hline Tobacco & 0.017 & 1,104 & .896 & $<.001$ \\
\hline Other illicit drugs & 0.527 & 1,104 & .470 & .005 \\
\hline SES & 0.075 & 1,104 & .784 & .001 \\
\hline WTAR & 3.058 & 1,104 & .083 & .029 \\
\hline \multicolumn{5}{|l|}{ Stop Signal Task- SSRT } \\
\hline Age-Group & 0.093 & 1,121 & .761 & .001 \\
\hline Cannabis frequency & 0.001 & 1,121 & .978 & $<.001$ \\
\hline Age-Group*Cannabis frequency & 0.155 & 1,121 & .694 & .001 \\
\hline Gender & 0.092 & 1,121 & .762 & .001 \\
\hline RT-18 & 4.289 & 1,121 & .040 & .034 \\
\hline Alcohol & 1.562 & 1,121 & .214 & .013 \\
\hline Tobacco & 3.804 & 1,121 & .053 & .030 \\
\hline Other illicit drugs & 0.771 & 1,121 & .382 & .006 \\
\hline SES & 0.124 & 1,121 & .725 & .001 \\
\hline WTAR & 0.810 & 1,121 & .370 & .007 \\
\hline
\end{tabular}


Figure S3: Scatter plot of cannabis days/week vs delayed prose recall score in adolescent and adult users. Scatter plot shows a trend significant relationship between cannabis days/week and prose recall (delayed) $\left(F(1,141)=3.276, p=.072, \eta_{p}{ }^{2}=0.023\right)$, but no interaction between age-group and cannabis days/week.

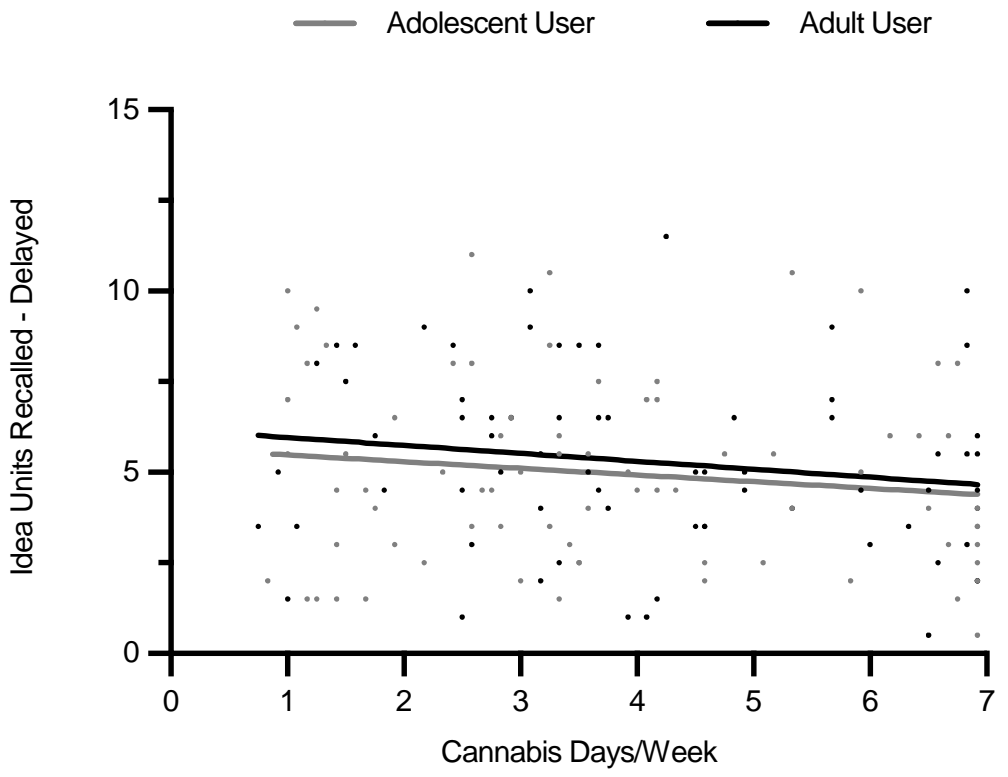

Figure S4: Scatter plot of cannabis days/week vs 3-back d' in adolescent and adult users. Scatter plot shows no significant relationship between cannabis days/week and d', and no interaction between age-group and cannabis days/week.

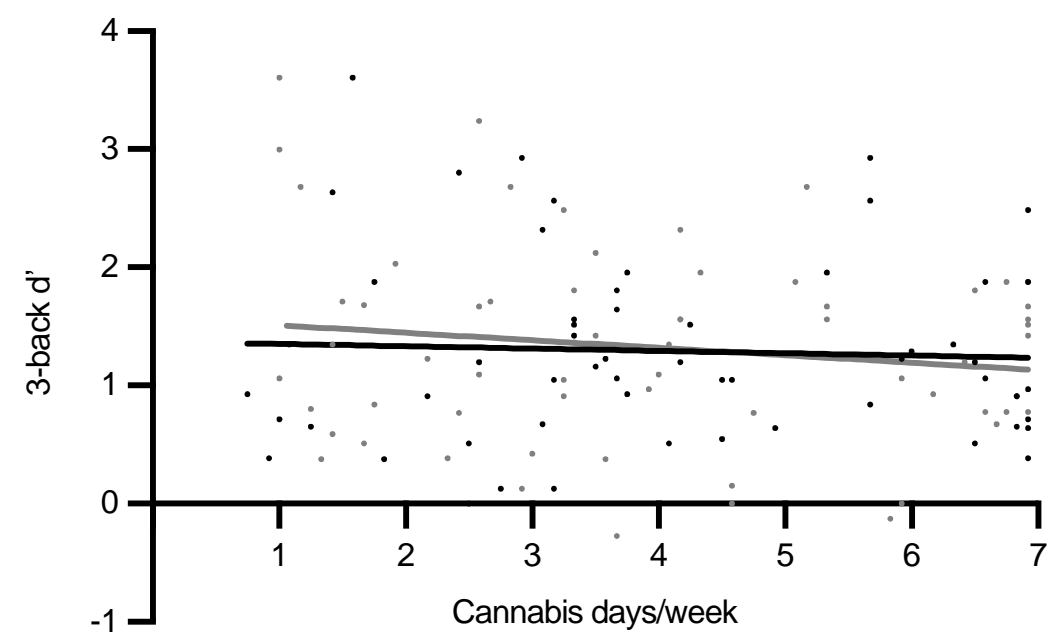


SUPPLEMENTARY CannTeen: cognitive function in adolescent and adult cannabis users and age-matched controls THIS IS A PRELIMINARY SCIENTIFIC WORK THAT HAS NOT BEEN PEER REVIEWED

Figure S5: Scatter plot of cannabis days/week vs SSRT in adolescent and adult users.

Scatter plot shows no significant relationship between cannabis days/week and SSRT, and no interaction between age-group and cannabis days/week.

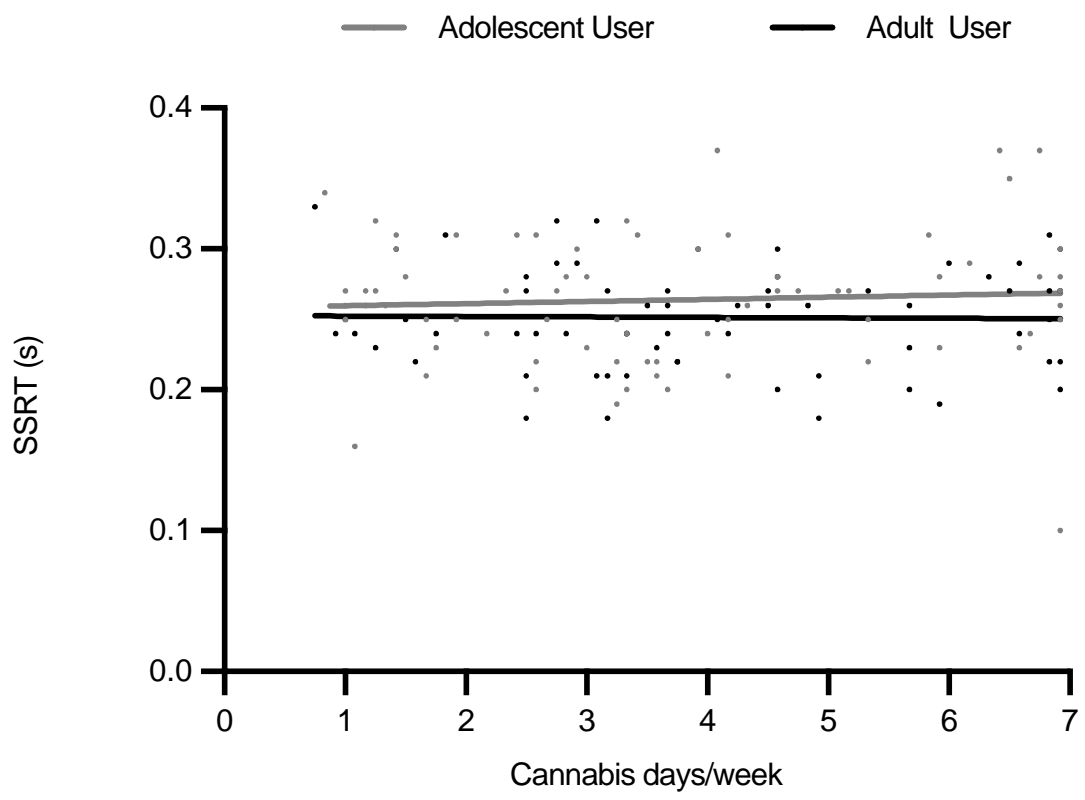


SUPPLEMENTARY CannTeen: cognitive function in adolescent and adult cannabis users and age-matched controls THIS IS A PRELIMINARY SCIENTIFIC WORK THAT HAS NOT BEEN PEER REVIEWED

\section{Immediate Recall Results}

Table S4. Mean immediate recall scores across the four groups. $95 \%$ confidence intervals are shown in brackets.

\begin{tabular}{ccccc}
\hline & $\begin{array}{c}\text { Adolescent } \\
\text { User }\end{array}$ & $\begin{array}{c}\text { Adolescent } \\
\text { Control }\end{array}$ & $\begin{array}{c}\text { Adult } \\
\text { User }\end{array}$ & $\begin{array}{c}\text { Adult } \\
\text { Control }\end{array}$ \\
\hline $\begin{array}{c}\text { Immediate } \\
\text { Recall }\end{array}$ & $5.618[4.964-6.273]$ & $5.889[5.355-$ & $6.109[5.507-$ & $7.508[6.762-8.254]$ \\
\hline
\end{tabular}

Table S5. Full results from ANOVA analysis of immediate recall in the prose recall task, ${ }^{*} p<0.05,{ }^{* *} p<0.01,{ }^{* * *} p<0.001$.

\begin{tabular}{lccccc}
\hline & $\mathbf{F}$ & $\mathbf{d f}$ & $\mathbf{p}$ & $\boldsymbol{\eta}_{\mathbf{p}}{ }^{2}$ & Group Differences \\
\hline Immediate Recall & & & & & \\
\hline User-Group & 6.704 & 1,268 & .010 & .024 & Controls $>$ Users $^{*}$ \\
Age-Group & 10.700 & 1,268 & .001 & .038 & Adults $>$ Adolescents $^{\star *}$ \\
User-Group*Age-Group & 3.064 & 1,268 & .081 & .011 & \\
\hline
\end{tabular}

Exploration of the trend User-Group*Age-Group interaction for prose recall (immediate) showed that within adults, users performed worse than controls $(t(131)=2.911, p=0.003, M D$ $=1.339)$, but within adolescents the difference was non-significant $(t(137)=0.597, p=0.550$, $\mathrm{MD}=0.270)$. 
SUPPLEMENTARY CannTeen: cognitive function in adolescent and adult cannabis users and age-matched controls

THIS IS A PRELIMINARY SCIENTIFIC WORK THAT HAS NOT BEEN PEER REVIEWED

Spatial $n$-back secondary outcome variable results

Table S6. Mean values for all spatial n-back secondary outcome variables across the four groups. 95\% confidence intervals are shown in brackets.

\begin{tabular}{|c|c|c|c|c|}
\hline & $\begin{array}{l}\text { Adolescent } \\
\text { User }\end{array}$ & $\begin{array}{l}\text { Adolescent } \\
\text { Control }\end{array}$ & $\begin{array}{l}\text { Adult } \\
\text { User }\end{array}$ & $\begin{array}{c}\text { Adult } \\
\text { Control }\end{array}$ \\
\hline 3-back RT & $.823[.769-.877]$ & $.772[.725-.819]$ & $.841[.793-.889]$ & $.887[.820-.935]$ \\
\hline 3-back \% Trial Correct & $70.7[67.4-74.0]$ & $70.6[67.5-73.6]$ & $70.3[67.1-70.3]$ & $72.4[68.7-76.1]$ \\
\hline \multirow[t]{2}{*}{ 2-back d' } & $2.022[1.808-$ & $2.063[1.819-$ & $2.256[2.014-$ & $2.248[1.948-$ \\
\hline & 2.235] & $2.307]$ & 2.497] & $2.547]$ \\
\hline 2-back RT & $.813[.759-866]$ & $.772[.719-.825]$ & $.819[.770-.868]$ & $.815[.752-.878]$ \\
\hline 2-back \% Trial Correct & $80.3[77.4-83.2]$ & $80.4[77.1-83.7]$ & $83.3[80.2-86.4]$ & $82.2[78.4-86.0]$ \\
\hline \multirow[t]{2}{*}{ 1-back d' } & $3.076[2.935-$ & $2.985[2.830-$ & $3.187[3.045-$ & 3.187 [3.028- \\
\hline & $3.217]$ & $3.140]$ & 3.330] & 3.344] \\
\hline 1-back RT & $.621[.585-.658]$ & $.580[.550-.611]$ & $.630[.590-.670]$ & $.645[.606-.685]$ \\
\hline 1-back \% Trial Correct & 92.5 [91.1-94.0] & $92.2[90.8-93.6]$ & 93.7 [92.4-95.0] & $93.5[92.0-95.1]$ \\
\hline \multirow[t]{2}{*}{ 0-back d' } & $3.641[3.553-$ & $3.603[3.491-$ & 3.669 [3.588- & $3.552[3.431-$ \\
\hline & $3.749]$ & $3.714]$ & $3.750]$ & 3.673] \\
\hline 0-back RT & $.483[.459-.507]$ & $.466[.445-.488]$ & $.477[.457-.497]$ & $.485[.466-.506]$ \\
\hline 0-back \% Trial Correct & 97.7 [96.9-98.5] & $97.3[96.3-98.3]$ & $98.0[97.3-98.6]$ & 96.9 [95.8-98.0] \\
\hline
\end{tabular}


Table S7. Full ANOVA results of spatial $n$-back task secondary outcome variables. ${ }^{*} p<0.05$, ${ }^{* *} \mathrm{p}<0.01,{ }^{* * *} \mathrm{p}<0.001$

$F \quad d f \quad p \quad \eta_{p}^{2} \quad$ Group Differences

\section{3-back RT}

\begin{tabular}{l} 
User-Group \\
Age-Group \\
User-Group*Age-Group \\
3-back\% Trials Correct \\
\hline User-Group
\end{tabular}

User-Group

User-Group*Age-Group

2-back d'

User-Group

Age-Group

User-Group*Age-Group

$\begin{array}{ccccc}0.082 & 1,233 & .775 & <.001 & \text { ns } \\ 5.682 & 1,233 & .018 & .024 & \text { Adolescents }<\text { Adults* } \\ 2.894 & 1,233 & .090 & .012 & \text { ns }\end{array}$

0.355

1,233

.552

.002

ns

$0.176 \quad 1,233$

.675

.001

.002

ns

ns

$0.458 \quad 1,233$

.499

.896

$<.001$

.012

ns

$2.802 \quad 1,233$

.096

$<.001$

ns

$0.039 \quad 1,233$

.843

.416

.003

.004

.002

ns

ns

ns

User-Group*Age-Group

.506

.747

$<.001$

ns

$2.073 \quad 1,233 \quad .151$

.009

ns

0.148

1,233

.700

.001

ns

1-back d'

User-Group

$0.337-1,233$

.540

.002

ns

Age-Group

$4.385 \quad 1,233$

.037

.018

0.361

1,233

.549

.002

Adolescents $<$ Adults ${ }^{*}$

User-Group^Age-Group

1-back RT

User-Group

0.498

1,233

.481

.002

.017

4.058

1,233

.045

.010

ns

.124

\section{Adolescents $<$ Adults*}

ns

1-back \% Trials Correct

User-Group
Age-Group
User-Group*Age-Group

0.149

1,233

.700

.001

ns

3.149

.077

.013

ns

$0.021 \quad 1,233$

.885

$<.001$

ns 
SUPPLEMENTARY CannTeen: cognitive function in adolescent and adult cannabis users and age-matched controls THIS IS A PRELIMINARY SCIENTIFIC WORK THAT HAS NOT BEEN PEER REVIEWED

$F \quad$ df $\quad p \quad \eta_{p}^{2} \quad$ Group Differences

0-back d'

User-Group

Age-Group

2.516

1,233

.114

.011

ns

User-Group*Age-Group

$0.101 \quad 1,233$

.751

$<.001$

ns

$0.432 \quad 1,233$

.512

.002

ns

0-back RT

User-Group

0.136

1,233

.712

.001

ns

Age-Group

$0.422 \quad 1,233$

.516

.002

ns

User-Group*Age-Group

$1.354 \quad 1,233$

.246

.006

ns

0-back \% Trials Correct

User-Group
Age-Group
User-Group^Age-Group

3.053

1,233

.082

.013

ns

$0.050 \quad 1,233$

.822

$<.001$

ns

$0.548 \quad 1,233$

.460

.002

ns 
Table S8. 1-back and 0-back Mann Whitney-U. For 1-back and 0-back data, assumptions were violated. Therefore, we conducted a set of non-parametric Mann Whitney-U tests between adult users and adult controls, and adolescent users and adolescent controls to further examine these results.

\begin{tabular}{lcc}
\hline & $\begin{array}{c}\text { Adolescents } \\
\text { Users vs. Controls }\end{array}$ & $\begin{array}{c}\text { Adults } \\
\text { Users vs. Controls }\end{array}$ \\
\hline 1-back d' & 1691.500 & 1652 \\
\hline$U$ & 0.473 & 0.867 \\
1-back RT & & 1485 \\
\hline$U$ & 1560 & 0.277 \\
$p$ & 0.163 & \\
1-back \% Trials Correct & & 1656 \\
\hline$U$ & 1710.500 & 0.884 \\
$p$ & 0.534 & \\
0-back d' & & 1475 \\
\hline$U$ & 1686 & 0.222 \\
$p$ & 0.422 & \\
0-back RT & & 1485 \\
\hline$U$ & & 0.277 \\
$p$ & 1645 & \\
0-back \% Trials Correct & 0.340 & 0.198 \\
\hline$U$ & &
\end{tabular}


For stop trial \% correct, 6 extreme outliers were found and winsorized. The extreme outliers were 1 adolescent user, 1 adolescent control and 4 adult controls. For go trial \% correct, 8 extreme outliers were found and winsorized. The extreme outliers were 1 adolescent user, 1 adolescent control, 4 adult users and 2 adult controls.

Table S9. Mean values for all stop signal secondary outcome variables across the four groups. 95\% confidence intervals are shown in brackets.

\begin{tabular}{ccccc}
\hline & $\begin{array}{c}\text { Adolescent } \\
\text { User }\end{array}$ & $\begin{array}{c}\text { Adolescent } \\
\text { Control }\end{array}$ & $\begin{array}{c}\text { Adult } \\
\text { User }\end{array}$ & $\begin{array}{c}\text { Adult } \\
\text { Control }\end{array}$ \\
\hline Mean SSD & $.302[.265-.338]$ & $.257[.215-.299]$ & $.321[.283-.359]$ & $.269[.229-.308]$ \\
Mean Go RT (s) & $.567[.534-.601]$ & $.513[.475-.552]$ & $.572[.537-.607]$ & $.520[.484-.556]$ \\
& & & & $.984[.979-.989]$ \\
Go Trial \% Correct & $.979[.974-.984]$ & $.992[.986-.998]$ & $.995[.990-1.001$ \\
& & & & \\
Stop Trial \% & $.504[.492-.516]$ & $.495[4.81-.509]$ & $.521[.508-.534]$ & $.498[.485-.512]$ \\
Correct & & & & \\
\hline
\end{tabular}


Table S10. Full results from ANOVA analyses of stop signal secondary variables. ${ }^{*} \mathrm{p}<0.05$, ${ }^{* *} p<0.01,{ }^{* * *} p<0.001, n s=$ non-significant.

\begin{tabular}{|c|c|c|c|c|c|}
\hline & $\mathbf{F}$ & df & $\mathbf{p}$ & $\eta_{p}^{2}$ & Group Differences \\
\hline \multicolumn{6}{|l|}{ Mean SSD } \\
\hline User-Group & 5.898 & 1,252 & .016 & .023 & Controls<Users* \\
\hline Age-Group & 0.609 & 1,252 & .436 & .002 & ns \\
\hline User-GroupAge-Group & 0.037 & 1,252 & .847 & $<.001$ & ns \\
\hline \multicolumn{6}{|l|}{ Mean Go RT } \\
\hline User-Group & 8.537 & 1,252 & .004 & .033 & Controls< Users ${ }^{\star *}$ \\
\hline Age-Group & 0.100 & 1,252 & .752 & $<.001$ & ns \\
\hline User-Group*Age-Group & 0.002 & 1,252 & .996 & $<.001$ & ns \\
\hline \multicolumn{6}{|l|}{ Go Trial \% Correct } \\
\hline User-Group & 19.501 & 1,252 & $<.001$ & .072 & Controls>Users ${ }^{* * *}$ \\
\hline Age-Group & 2.203 & 1,252 & .139 & .009 & ns \\
\hline User-Group^Age-Group & 0.041 & 1,252 & .840 & $<.000$ & ns \\
\hline \multicolumn{6}{|l|}{ Stop Trial \% Correct } \\
\hline User-Group & 5.679 & 1,252 & .018 & .022 & Controls $<$ Users ${ }^{*}$ \\
\hline Age-Group & 2.292 & 1,252 & .131 & .009 & ns \\
\hline User-Group*Age-Group & 1.094 & 1,252 & .297 & .004 & ns \\
\hline
\end{tabular}

Stop signal Go Trial \% Correct: Mann Whitney-U results

For go trial \% correct, it was found that the assumption of normality of residuals was violated. Therefore, we conducted a set of non-parametric Mann Whitney-U tests to further examine these results. This confirmed that controls correctly responded to go trials at a higher proportion than users $(U=7202, p=.001)$. In contrast to the ANOVA result, another comparison revealed an effect of age-group, with adults correctly responding to go trials at a higher proportion than adolescents $(U=7786.5, p=.014)$. Separate comparisons of adolescent controls vs adolescent users $(U=188877.5, p=.033)$, and adult controls vs adult controls $(U=1717.5, p=.007)$ revealed that in both age-groups, controls correctly responded to a higher proportion of go trials. 
Table S11. Full results from $2 \times 2 \times 2$ mixed ANOVA of immediate and delayed prose recall, ${ }^{*} p<0.05$, ${ }^{* *} \mathrm{p}<0.01,{ }^{* * *} \mathrm{p}<0.001$

\begin{tabular}{|c|c|c|c|c|c|}
\hline & $\mathbf{F}$ & df & $\mathbf{p}$ & $\eta_{p}^{2}$ & Group Differences \\
\hline \multicolumn{6}{|l|}{ Prose recall } \\
\hline User-Group & 4.981 & 1,251 & 0.027 & 0.019 & Controls>users* \\
\hline Age-Group & 7.053 & 1,251 & 0.008 & 0.027 & Adults>adolescents* \\
\hline Time & 139.669 & 1,251 & $<0.001$ & 0.358 & Immediate>delayed ${ }^{\star \star *}$ \\
\hline User-Group*Age-Group & 2.810 & 1,251 & 0.095 & 0.011 & ns \\
\hline User-Group*Time & 0.291 & 1,251 & 0.590 & 0.001 & ns \\
\hline Age-Group*Time & 2.078 & 1,251 & 0.151 & 0.008 & ns \\
\hline $\begin{array}{l}\text { User-Group*Age- } \\
\text { Group*Time }\end{array}$ & 0.054 & 1,251 & 0.816 & $<0.001$ & ns \\
\hline
\end{tabular}

Table S12. Correlations between our primary outcome variables (3-back d prime, stop signal reaction time, delayed recall) and age-of-onset, only in adult users. There were no significant associations.

\begin{tabular}{cccc}
\hline & $\mathbf{r}$ & $\mathbf{p}$ & $\mathbf{n}$ \\
\hline d' 3-back (N-Back) & -0.040 & 0.767 & 58 \\
SSRT (Stop Signal) & 0.006 & 0.960 & 67 \\
& & & \\
$\begin{array}{l}\text { Delayed Recall } \\
\text { (Prose Recall) }\end{array}$ & -0.064 & 0.607 & 68 \\
\hline
\end{tabular}




\section{Section 6: Substance Use Variables}

Table S13. Lifetime drug use variables for adolescent controls, adolescent users, adult controls and adult users. Use of e-cigarettes in past 12 months is missing for one adolescent user

\begin{tabular}{|c|c|c|c|c|}
\hline & $\begin{array}{l}\text { Adolescent } \\
\text { user }\end{array}$ & $\begin{array}{l}\text { Adolescent } \\
\text { control }\end{array}$ & Adult user & Adult control \\
\hline Alcohol: ever used & $75(98.7 \%)$ & $61(96.8 \%)$ & $71(100.0 \%)$ & $64(100.0 \%)$ \\
\hline Alcohol: used in past 12 weeks: & $71(93.4 \%)$ & $55(87.3 \%)$ & $67(94.4 \%)$ & $61(95.3 \%)$ \\
\hline Tobacco: ever used & $74(97.4 \%)$ & $49(77.8 \%)$ & $66(93.0 \%)$ & $58(90.6 \%)$ \\
\hline Tobacco: used in past 12 weeks: & 59 (77.6\%) & $18(28.6 \%)$ & $39(54.9 \%)$ & $18(28.1 \%)$ \\
\hline Ecstasy: ever used & $54(71.1 \%)$ & $5(7.9 \%)$ & $52(73.2 \%)$ & $21(32.8 \%)$ \\
\hline Ecstasy: used in past 12 weeks & $35(46.1 \%)$ & $1(1.6 \%)$ & $22(31.0 \%)$ & $2(3.1 \%)$ \\
\hline Laughing gas: ever used & $66(86.8 \%)$ & $22(34.9 \%)$ & $43(60.6 \%)$ & $24(37.5 \%)$ \\
\hline Laughing gas: used in past 12 weeks & $37(48.7 \%)$ & $4(6.3 \%)$ & $5(7.0 \%)$ & $1(1.6 \%)$ \\
\hline E-cigarette: ever used & $50(65.8 \%)$ & $33(52.4 \%)$ & $36(50.7 \%)$ & $16(25.0 \%)$ \\
\hline E-cigarette: used in past 12 weeks & $9(12.0 \%)$ & $10(15.9 \%)$ & $9(12.7 \%)$ & $3(4.7 \%)$ \\
\hline Ketamine: ever used & $48(63.2 \%)$ & $7(11.1 \%)$ & $35(49.3 \%)$ & $10(15.6 \%)$ \\
\hline Ketamine: used in past 12 weeks & 36 (47.4\%) & $4(6.3 \%)$ & $10(14.1 \%)$ & $1(1.6 \%)$ \\
\hline LSD: ever used & $29(38.2 \%)$ & $1(1.6 \%)$ & $27(38.0 \%)$ & $3(4.7 \%)$ \\
\hline LSD: used in past 12 weeks & $10(13.2 \%)$ & $0(0.0 \%)$ & $5(7.0 \%)$ & $0(0.0 \%)$ \\
\hline Cocaine: ever used & $28(36.8 \%)$ & $1(1.6 \%)$ & $52(73.2 \%)$ & $18(28.1 \%)$ \\
\hline Cocaine: used in past 12 weeks & $13(17.1 \%)$ & $1(1.6 \%)$ & $23(32.4 \%)$ & $6(9.4 \%)$ \\
\hline Magic mushrooms: ever used & $16(21.1 \%)$ & $1(1.6 \%)$ & $39(54.9 \%)$ & $12(18.8 \%)$ \\
\hline $\begin{array}{l}\text { Magic mushrooms: used in past } 12 \\
\text { weeks }\end{array}$ & $3(3.9 \%)$ & $0(0.0 \%)$ & $6(8.5 \%)$ & $3(4.7 \%)$ \\
\hline Alprazolam 'Xanax': ever used & $23(42.6 \%)$ & $0(0.0 \%)$ & $10(17.2 \%)$ & $3(5.0 \%)$ \\
\hline $\begin{array}{l}\text { Alprazolam 'Xanax': used in past } 12 \\
\text { weeks }\end{array}$ & $4(7.5 \%)$ & $0(0.0 \%)$ & $2(3.4 \%)$ & $0(0.0 \%)$ \\
\hline Diazepam 'Valium': ever used & $13(24.1 \%)$ & $0(0.0 \%)$ & $12(21.1 \%)$ & $6(10.0 \%)$ \\
\hline $\begin{array}{l}\text { Diazepam 'Valium': used in past } 12 \\
\text { weeks }\end{array}$ & $3(5.7 \%)$ & $0(0.0 \%)$ & $0(0.0 \%)$ & $4(1.8 \%)$ \\
\hline Amphetamine: ever used & $13(17.1 \%)$ & $1(1.6 \%)$ & $21(29.6 \%)$ & $2(3.1 \%)$ \\
\hline Amphetamine: used in past 12 weeks & $5(6.6 \%)$ & $0(0.0 \%)$ & $4(5.6 \%)$ & $0(0.0 \%)$ \\
\hline Synthetic cannabinoids: ever used & $5(6.6 \%)$ & $0(0.0 \%)$ & $11(15.5 \%)$ & $2(3.1 \%)$ \\
\hline $\begin{array}{l}\text { Synthetic cannabinoids: used in past } \\
12 \text { weeks }\end{array}$ & $0(0.0 \%)$ & $0(0.0 \%)$ & $0(0.0 \%)$ & $0(0.0 \%)$ \\
\hline Methamphetamine: ever used & $0(0.0 \%)$ & $0(0.0 \%)$ & $2(2.8 \%)$ & $1(1.6 \%)$ \\
\hline $\begin{array}{l}\text { Methamphetamine: used in past } 12 \\
\text { weeks }\end{array}$ & $0(0.0 \%)$ & $0(0.0 \%)$ & $1(1.4 \%)$ & $0(0.0 \%)$ \\
\hline Heroin: ever used & $0(0.0 \%)$ & $0(0.0 \%)$ & $0(0.0 \%)$ & $1(1.6 \%)$ \\
\hline Heroin: used in past 12 weeks & $0(0.0 \%)$ & $0(0.0 \%)$ & $0(0.0 \%)$ & $0(0.0 \%)$ \\
\hline Crack cocaine: ever used & $0(0.0 \%)$ & $0(0.0 \%)$ & $2(2.8 \%)$ & $0(0.0 \%)$ \\
\hline $\begin{array}{l}\text { Crack cocaine: used in past } 12 \\
\text { weeks }\end{array}$ & $0(0.0 \%)$ & $0(0.0 \%)$ & $0(0.0 \%)$ & $0(0.0 \%)$ \\
\hline
\end{tabular}


SUPPLEMENTARY CannTeen: cognitive function in adolescent and adult cannabis users and age-matched controls

THIS IS A PRELIMINARY SCIENTIFIC WORK THAT HAS NOT BEEN PEER REVIEWED

\section{Section 7: Supplementary Discussion}

Verbal episodic memory

One previous cross-sectional study comparing adolescent controls, alcohol users and cannabis users reported a delayed recall user impairment with a large effect size $(d=0.84)$, which remained significant after adjusting for covariates (26). However, they did not include SES or premorbid IQ as covariates, although their groups were matched on these variables (26).

We did not find strong evidence for a differential relationship between cannabis use and VEM in adolescents and adults, while previous work found that people with an earlier age of cannabis use onset recalled less words than those with a later age of onset $(12,26)$. This may be related to the different study design. In our study, adolescent users had earlier ages of onset and shorter durations of use than adult users; while in previous research, adult participants with an earlier age of onset had longer durations of use. The characteristics of these previous studies, and others like them, may bias findings in favour of negative associations between age-of-onset and impaired outcomes.

\section{Association with cannabis use frequency}

In our analysis of the user-group, we found only a trend association between cannabis use frequency and delayed recall. In contrast, Solowij and colleagues (25) found a strong negative correlation cannabis use frequency and delayed recall, where a greater frequency of cannabis use was significantly associated with poorer recall. Similarly, a meta-analysis found that heavy users, who used cannabis over 20 times a month, performed significantly worse on a collection of memory tasks (including VEM) than moderate or light users (27). Collectively, these results suggest more frequent cannabis use is associated with worse VEM. 
SUPPLEMENTARY CannTeen: cognitive function in adolescent and adult cannabis users and age-matched controls THIS IS A PRELIMINARY SCIENTIFIC WORK THAT HAS NOT BEEN PEER REVIEWED

\section{References}

1. Vakil E, Greenstein Y, Blachstein H. Normative data for composite scores for children and adults derived from the Rey Auditory Verbal Learning Test. Clin Neuropsychol. 2010;24(4):662-77.

2. Curry JF, Logue PE, Butler B. Child and adolescent norms for Russell's revision of the Wechsler Memory Scale. J Clin Child Psychol. 1986;15(3):214-20.

3. Sowell ER, Delis D, Stiles J, Jernigan TL. Improved memory functioning and frontal lobe maturation between childhood and adolescence: a structural MRI study. J Int Neuropsychol Soc. 2001;7(3):312-22.

4. Broyd SJ, van Hell HH, Beale C, Yuecel M, Solowij N. Acute and chronic effects of cannabinoids on human cognition-a systematic review. Biol Psychiatry. 2016;79(7):557-67.

5. Jacobus J, Squeglia LM, Infante MA, Castro N, Brumback T, Meruelo AD, et al. Neuropsychological performance in adolescent marijuana users with co-occurring alcohol use: A three-year longitudinal study. Neuropsychology. 2015;29(6):829.

6. Duperrouzel JC, Hawes SW, Lopez-Quintero C, Pacheco-Colón I, Coxe S, Hayes T, et al. Adolescent cannabis use and its associations with decision-making and episodic memory: Preliminary results from a longitudinal study. Neuropsychology. 2019;33(5):701.

7. Schutte AR, Spencer JP. Tests of the Dynamic Field Theory and the Spatial Precision Hypothesis: Capturing a Qualitative Developmental Transition in Spatial Working Memory. J Exp Psychol Hum Percept Perform. 2009;35(6):1698-725.

8. Schutte AR, Spencer JP, Schöner G. Testing the Dynamic Field Theory: Working Memory for Locations Becomes More Spatially Precise over Development. Child Dev. 2003;74(5):1393417.

9. Cowan N, Saults JS, Morey CC. Development of working memory for verbal-spatial associations. J Mem Lang. 2006;55(2):274-89.

10. Tervo-Clemmens B, Simmonds D, Calabro FJ, Day NL, Richardson GA, Luna B. Adolescent cannabis use and brain systems supporting adult working memory encoding, maintenance, and retrieval. Neuroimage. 2018;169(January 2017):496-509.

11. Harvey MA, Sellman JD, Porter RJ, Frampton CM. The relationship between non-acute adolescent cannabis use and cognition. Drug Alcohol Rev. 2007;26(3):309-19.

12. Becker MP, Collins PF, Schultz A, Urošević S, Schmaling B, Luciana M. Longitudinal changes in cognition in young adult cannabis users. J Clin Exp Neuropsychol. 2018;40(6):529-43.

13. Tamm L, Menon V, Reiss AL. Maturation of brain function associated with response inhibition BrowZine Journal Cover. J Am Acad Child Adolesc Psychiatry. 2002;41(10):1231-8.

14. Booth JR, Burman DD, Meyer JR, Lei Z, Trommer BL, Davenport ND, et al. Neural development of selective attention and response inhibition. Neuroimage. 2003;20(2):737-51.

15. Luna B, Padmanabhan A, O'Hearn K. What has fMRI told us about the Development of Cognitive Control through Adolescence? Brain Cogn. 2009;72:101-13.

16. Lawn W, Mokrysz C, Borissova A, Lees R, Petrilli K, Bloomfield M, et al. STUDY PROTOCOL CANNTEEN: HOW DOES LONG-TERM CANNABIS USE AFFECT TEENAGERS' AND ADULTS' COGNITION, MENTAL HEALTH AND BRAINS. OSF. 2020. 
SUPPLEMENTARY CannTeen: cognitive function in adolescent and adult cannabis users and age-matched controls THIS IS A PRELIMINARY SCIENTIFIC WORK THAT HAS NOT BEEN PEER REVIEWED

17. Verbruggen F, Aron AR, Band GPH, Beste C, Bissett PG, Brockett AT, et al. A consensus guide to capturing the ability to inhibit actions and impulsive behaviors in the stop-signal task. Elife. 2019;8:1-26.

18. Verbruggen F, Logan GD. Response inhibition in the stop-signal paradigm. Trends Cogn Sci. 2008;12(11):418-24.

19. Matzke D, Verbruggen F, Logan GD. The Stop-Signal Paradigm. Stevens' Handbook of Experimental Psychology and Cognitive Neuroscience. 2018. 1-45 p.

20. Haatveit BC, Sundet K, Hugdahl K, Ueland T, Melle I, Andreassen OA. The validity of d prime as a working memory index: Results from the Bergen n-back task. J Clin Exp Neuropsychol. 2010;32(8):871-80.

21. Robinson SM, Sobell LC, Sobell MB, Leo GI. Reliability of the Timeline Followback for cocaine, cannabis, and cigarette use. Psychol Addict Behav. 2014;

22. De Haan L, Kuipers E, Kuerten Y, Van Laar M, Olivier B, Cornelis Verster J. The rT-18: a new screening tool to assess young adult risk-taking behavior. Int J Gen Med. 2011;

23. Holdnack HA. Wechsler test of adult reading: WTAR. San Antonio, TX Psychol Corp. 2001;

24. Bohn M., Babor HRK. The Alcohol Use Disorders Identification Test (AUDIT): validation of a screening instrument for use in medical settings. J Stud Alcohol Drugs. 1995;56(4):423-32.

25. Adamson SJ, Kay-Lambkin FJ, Baker AL, Lewin TJ, Thornton L, Kelly BJ, et al. An improved brief measure of cannabis misuse: the Cannabis Use Disorders Identification Test-Revised (CUDITR). Drug Alcohol Depend. 2010;110(1-2):137-43.

26. Solowij N, Jones KA, Rozman ME, Davis SM, Ciarrochi J, Heaven PCL, et al. Verbal learning and memory in adolescent cannabis users, alcohol users and non-users. Psychopharmacology (Berl). 2011;216(1):131-44.

27. Schoeler T, Kambeitz J, Behlke I, Murray R, Bhattacharyya S. The effects of cannabis on memory function in users with and without a psychotic disorder: findings from a combined meta-analysis. Psychol Med. 2016;(1):177-88. 